AIAA Space 2010 Conference,

August 31 - September 2, 2010, Anaheim, California

\title{
Integration Process for the Habitat Demonstration Unit
}

\author{
T.R.Gill' ${ }^{1}$ J. C. Merbitz ${ }^{2}$ \\ NASA Kennedy Space Center, KSC, FL 32899 \\ K. J. Kennedy ${ }^{3}$, T. O. Tri ${ }^{4}$ \\ NASA Johnson Space Center, Houston, TX 77058 \\ A. S. Howe ${ }^{5}$ \\ NASA Jet Propulsion Laboratory, Pasadena CA 91109
}

\section{Abstract}

The Habitat Demonstration Unit (HDU) is an experimental exploration habitat technology and architecture test platform designed for analog demonstration activities. The HDU project has required a team to integrate a variety of contributions from NASA centers and outside collaborators. A notable challenge the HDU project has faced has been integrating these disparate efforts into a cohesive architecture. To complete the development of the HDU, from conception in June 2009 to rollout for operations in July 2010, a cohesive integration strategy has been developed. An integration strategy provides the necessary steps to integrate the various systems of HDU and the payloads, such as the Geology Lab, that those systems will support. The utilization of interface design standards and uniquely tailored reviews have allowed for an accelerated design process. Scheduled activities include early fit-checks and the utilization of a habitat avionics test bed prior to equipment installation into HDU. A coordinated effort to utilize modeling and simulation systems has aided in design and integration concept development. Modeling tools have been effective in hardware systems layout, cable routing and length estimation, and human factors analysis. Decision processes on the shell development, including the assembly sequence and the transportation, have been fleshed out early on HDU designs to maximize the efficiency of both integration and field operations. Incremental test operations leading up to an integrated systems test has allowed for an orderly systems test program. The HDU will begin its journey as an emulation of a Pressurized Excursion Module (PEM) for 2010 field testing. It may evolve to a Pressurized Core Module (PCM) or a habitat and laboratory combination for 2011 and later field tests, depending on agency architecture decisions. The HDU deployment will vary slightly from current lunar architecture plans to include developmental hardware and software items and additional systems utilized as opportunities for technology demonstration. Another notable HDU challenge has been designing with the idea that the team be prepared for the integration of presently unanticipated systems. Results of the HDU field tests will influence future designs of habitat systems

\section{Background}

A technique being utilized in NASA's exploration architecture analysis is analog testing of a lunar or Mars environment in desert locales. Running through potential "day in the life" scenarios at an exploration outpost with prototype equipment allows designers insight into the utilization of the proposed systems and refines architecture and operations concepts. A series of Desert Research and Technology Studies (RaTS) have been held in locations such as Moses Lake, Washington and Black Point Lava Flow, Arizona, where the most recent test in September 2009 was performed with a Space Exploration Vehicle rover, and a fourteen day lunar excursion was practiced. The 2010 session of Desert RaTS is planned again for Black Point Lava Flow where two Space Exploration Vehicle (SEV) rovers will operate together along with a full scale habitat prototype, the HDU, to allow for a 14-21 day mission. A graphic example of the proposed lunar architecture under evaluation at the Desert RaTS 2010 campaign is depicted below in Figure 1. The Pressurized Excursion Module (PEM) to be represented by the HDU in 2010 is depicted in the center. One difference in the version of the PEM depicted in that figure from the HDU version of the PEM is that the HDU version will not accommodate commodity storage tanks on its roof. As the name implies, the

1 Engineer, Lunar Systems Division, Mail Code LX-M,

2 Engineer, Lunar Systems Division, Mail Code LX-M,

3 Architect, Systems Architecture and Integration Office, Mail Code EA3

4 Engineer, Systems Architecture and Integration Office, Mail Code EA3

5 Architect, Mission Systems Concepts, Mail Code 312E 
application for the PEM during lunar excursions is to provide research and habitation functionality in a mobile outpost for excursion missions.

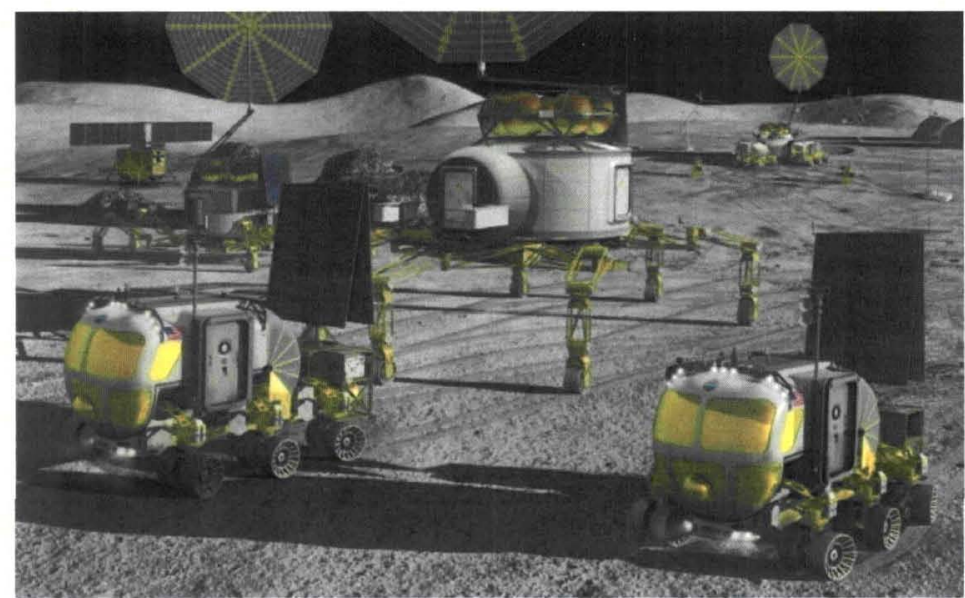

Figure 1 - Example of a lunar architecture analyzed through Desert RaTS campaigns.

\section{Integration Strategy}

The HDU project has required integrating a variety of contributions from NASA centers and has posed a challenge in integrating these disparate efforts into a cohesive architecture. The HDU begins its work as an emulation of a Pressurized Excursion Module (PEM) for 2010 field testing. A PEM is a mobile laboratory that works in concert with crews in SEV rovers for science sample analysis and maintenance tasks rather than a traditional habitat. Preliminary plans were to evolve to a Pressurized Core Module (PCM), which is more of a traditional habitat with crew accommodations, for 2011 and later field tests, but the changing of priorities in NASA direction may influence the HDU configuration to a more flexible version of a habitat and laboratory. The HDU deployment is not the same configuration as either the PCM or the PEM as conceived in current Constellation lunar architecture plans. There are some developmental hardware and software items that are not available due to cost and technology availability and some items that are only functional simulations. Conversely, there are additional items available for the HDU that are opportunities for demonstration, which are originally unanticipated systems than can be plugged into the HDU architecture if there are common goals and objectives. Results of the HDU field tests will influence future designs of exploration habitats.

\section{A. Design Standards}

To be able to accomplish integration and form the foundation for future evolution of the hardware, an integration plan was developed for potential current and future contributors to the HDU to communicate design interface standards. The HDU project team aligned as much as possible with interfaces, hardware, and experience of SEV rover team. Specifically, HDU utilized common molds for the hatches used for the SEV rover. Additionally, the team utilized one standard "orange slice" shell section design to simplify shell manufacturing. Most importantly, the team defined common standards for core subsystems to simplify the addition of other systems later. These included the utilization of $120 \mathrm{VAC}$ for the primary power system, common bolt hole patterns on shell ribs, and commercial modular framing kits for secondary structure. Additionally, the HDU project team relied on the Lunar Surface System (LSS) Habitat team to align HDU implementation with habitation planning. These standards are not intended to be detailed interface specifications normally seen with flight hardware, but there is enough definition included to enable a future HDU contributor to build a system that will integrate with HDU systems. 


\section{B. Risk Mitigation}

In concert with the establishment of the interface definitions, the HDU team utilized scheduled pre-integration activities, integration tools, and $m$ to buy-down risk prior to integration of systems within the HDU shell. Project reviews, milestones, fit-check and bench-top test opportunities, integration and test activities, and field operations were among the items tracked in a comprehensive HDU master project schedule, managed in Microsoft Project.

\section{Scheduled Activities}

Simulation Activities

The HDU project team has utilized simulation early in the development flow to test form, fit, integration, assembly and basic functions as sub-system designs matured. These simulation opportunities have been present throughout the design lifecycle from concept to implementation. The first sessions occurred as soon as HDU shell data and PEM system design data became available. Periodic synchronization events occurred during development and extended through evaluation of the field outings such as the deployment in the field and the docking operations with the SEV rover. The events included updates to models and simulations from end item developers and the HDU shell model to reflect current operations concepts and current system designs.

Mechanical Activities

The HDU project team utilized fit-check opportunities in the development flow at JSC to allow hardware to be temporarily installed for form and fit. These opportunities occurred from days to weeks prior to the hardware installation date depending on complexity and availability.

\section{Electrical and Software Activities}

The HDU project team utilized the Habitat Test-bed (HaT) in JSC Building 220 as a bench-top platform for early PEM avionics, communications, power, and other systems prior to final installation of hardware/software within the HDU shell. These opportunities occurred between a few weeks to a few days prior to the hardware installation date depending on complexity and availability of the subsystem. This HaT asset allowed for early system testing to debug interface and software problems before the hardware was installed. Occasional use of software models of hardware was utilized in order to retire software development risk.

\section{Integration Tools}

The HDU project team compiled a Master Equipment List (MEL) adapted from the Pressurized Excursion Module (PEM). This list was tailored for the HDU implementation of the PEM and includes a system by system break-down of item name, mass, volume, power and a flag whether it is in scope of the PEM or the Pressurized Core Module (PCM), or is an opportunity for demonstration. The latter category was utilized for items that are not on the PEM or PCM MELs but are available for evaluation during the development, integration, or field operations phases at HDU project team discretion. Additionally, an integrated set of schematics was developed using AutoCAD to both plan the wiring of the systems and to reflect wiring updates made during installation operations.

\section{Modeling and Simulation Tools}

The HDU project has utilized a coordinate system to assist in the placement of systems within the HDU during integration analysis and for location labeling of the systems and other equipment during operations. The scheme for the coordinate systems is depicted below in Figure 2. 


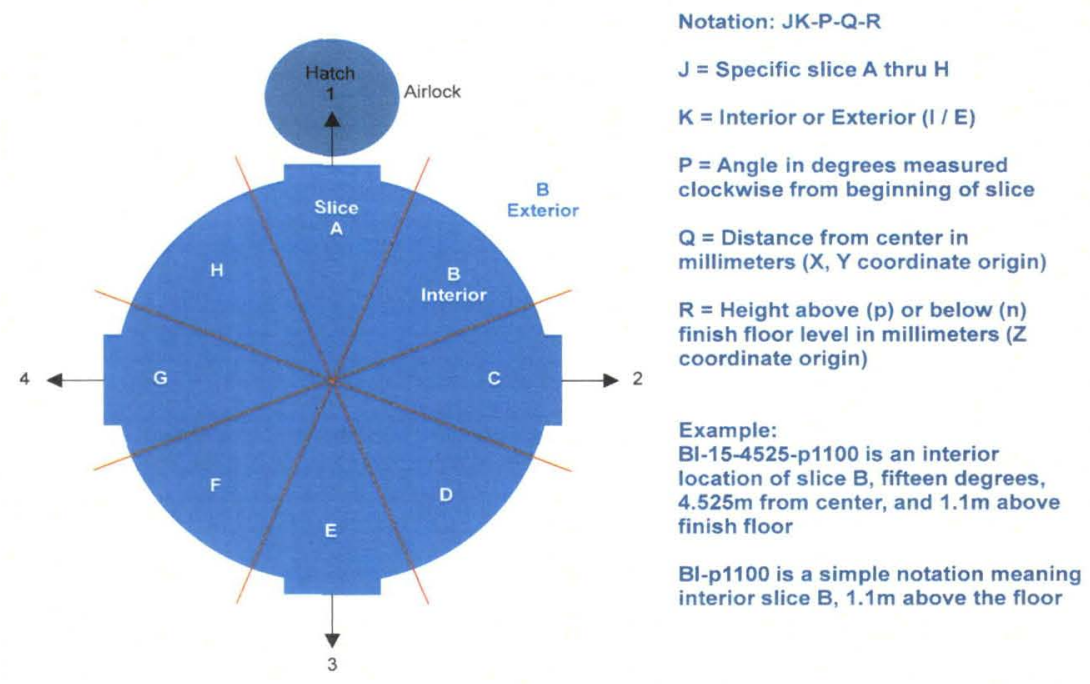

Figure 2 - HDU Coordinate System

Additionally, the HDU project team utilized Constellation simulation tools to assist in the design layout of HDU systems, factoring in both the intended layouts of the PEM and the systems available for the HDU project. Computer Aided Design (CAD) representations of the various HDU systems were used during an Integration Review process to determine where the systems would be located internal and external to the HDU shell prior to beginning the touch-labor integration effort. The $\mathrm{CAD}$ model was used for layout of subsystems and evaluation of sizing, cable lengths, and operational issues prior to physical integration. After coordinating with each system for initial recommendations on placing systems most effectively and conveniently, two integration reviews were held to include the entire team where the virtual model of the HDU was utilized. Continuing into the physical integration phase, the model has been continually updated to reflect changes done in the field to provide a starting point for future planning activities. An example of the utilization of CAD in the development of one of the HDU work stations, the General Maintenance Work Station, is detailed in the following section.

The specific tools used to support HDU vary throughout the project lifecycle. Initial work utilized Data Presentation and Visualization (DPV) capabilities in the Exploration Visualization Environment (EVE) and Distributed Observer Network (DON) to integrate and share system concepts. Data within these environments will consist of engineering models and other $\mathrm{CAD}$ data and has been updated regularly to ensure that the simulations match current designs. The JSC Habitat Test-bed (HaT) is using the base simulation tool provided by the Integrated Mission Simulation (IMSim) team for system and subsystem simulation. Adding the distributed IMSim capabilities to support $\mathrm{HAB}$ and $\mathrm{HaT}$ interactions in the field should not be a significant challenge.

Finally, the HDU project team has utilized Constellation software simulation and verification and validation tools to assist in the design, verification and validation, and integration of HDU "flight" software and Habitat Systems Management software systems, factoring in expected command and telemetry interfaces as well as software-to-software interfaces.

\section{CAD Model Utilization for General Maintenance Work Station}

Before the use of computers, creating two-dimensional drawings by hand, using paper, pencils, and rulers was very time consuming and tedious as each view and detail had to be created uniquely. One of the greatest technological leaps in design engineering came many years after the first computers were developed by means of two-dimensional (2-D) drafting software. Computer drafting software was step towards the amazing engineering software that exists today. Although quite an improvement from hand drawn drawings, using computers to create computer aided drawings (CAD) still took a lot of time. However, these programs did allow designers to copy, enlarge, and modify original drawings to display new details or view. While 2-D drafting software improved the way engineering and drawing packages were created, no software has had an impact on engineering like three dimensional (3-D) CAD.

The ability to create an engineering product three dimensionally has allowed design engineers to do so much more than just draw pictures for fabrication. Using 3-D software not only allows engineers to create individual 3-D models for all unique components, it allows engineers to use those models to fit check components, perform material 
and load analysis, and finally put together final assemblies. The utilization of 3-D modeling greatly assisted NASA from project conception to finalized product in a compressed development timeline in the Habitation Demonstration Unit project.

Because the HDU project team is comprised of team members located at different NASA centers throughout the country, the team has collaborated on a weekly basis to define the different sub-systems, goals, and requirements. However, though communication through meetings and email play a crucial role in ensuring all team members stay informed of the overall HDU progress, there comes a time when all subsystems must come together during the integration phase of the project. Complex design integration requires several design phases, and to gain a visual perspective during each phase of the design effort, the use of 3-D CAD modeling allowed the team to design, test, and fit check each component necessary to ensure compatibility. In the case of HDU, several tools were utilized but Pro Engineer was the primary tool.

An excellent example of the utilization of 3-D CAD during the design cycle is the General Maintenance Work Station (GMWS). When the assignment for GMWS development was received by NASA/Kennedy Space Center Prototype Shop team, the HDU project team gave a height requirement, requested an electric hoist, storable table, task lighting, and requested that some storage areas be designed into the work station. After obtaining 3-D modeling information pertaining to the section the GMWS would be installed and the surrounding systems, the GMWS subsystem team began the design process. The conceptual progress of the design was presented in weekly status forums with the integrated HDU team as well as Test Configuration Review in May 2010 to be able to communicate any impacts from other systems and vice versa.

Beginning with the GMWS table, the requirements defined the table to be comprised of two leafs ( 30 " x 30 ") that would form a completed 60 " x 30 " fully deployed table. Because the HDU project team had requested storage areas as well, the GMWS design team decided to incorporate storage shelves that would also have a dual role as the GMWS table attach/pivot point. The initial design is seen in Figure 3 below.
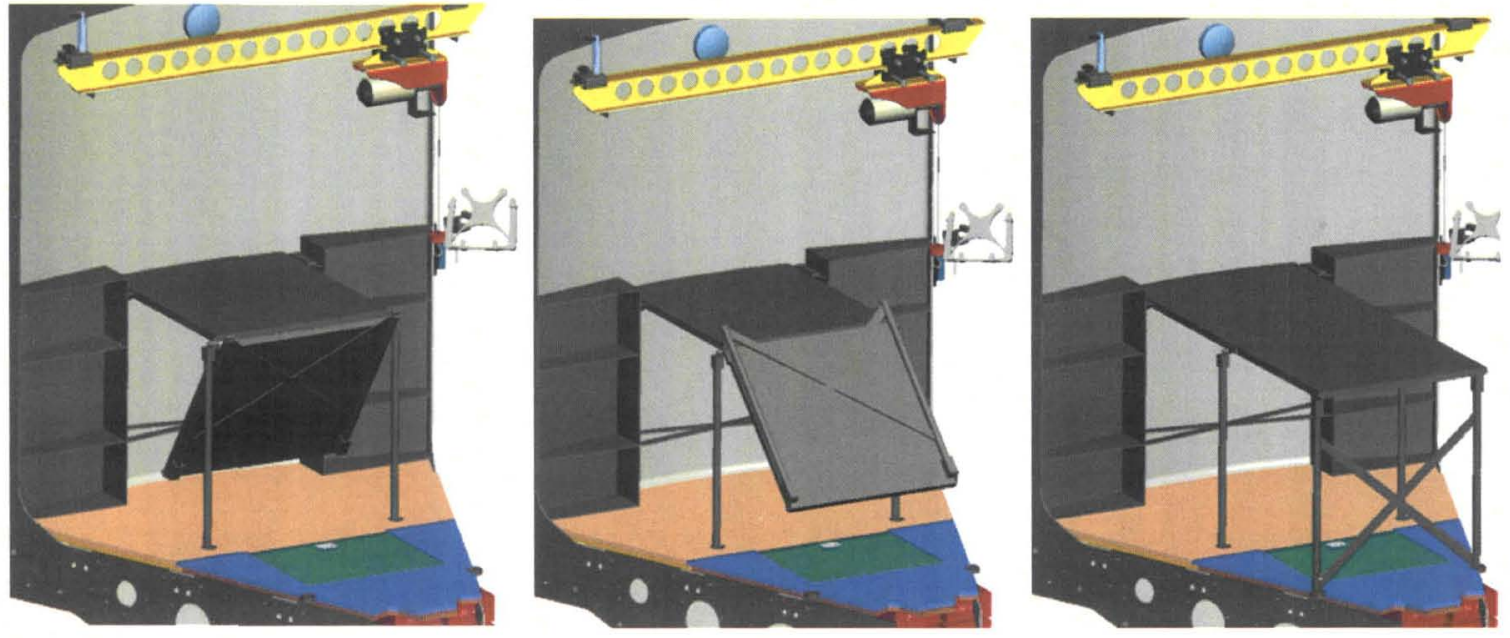

Figure 3 - GWMS Initial Design

When this initial concept was presented to the team, new clearance and storage requirements that were not originally delivered to the team were defined. Although a lot of work had already gone into the design of the table, the use of 3-D CAD software allowed the designers to make small adjustments to the width and lengths of the table, as well as the depth and sizes of the storage shelves to accommodate the new requirements. The final products of the table and storage shelves are shown in Figure 4 below. 

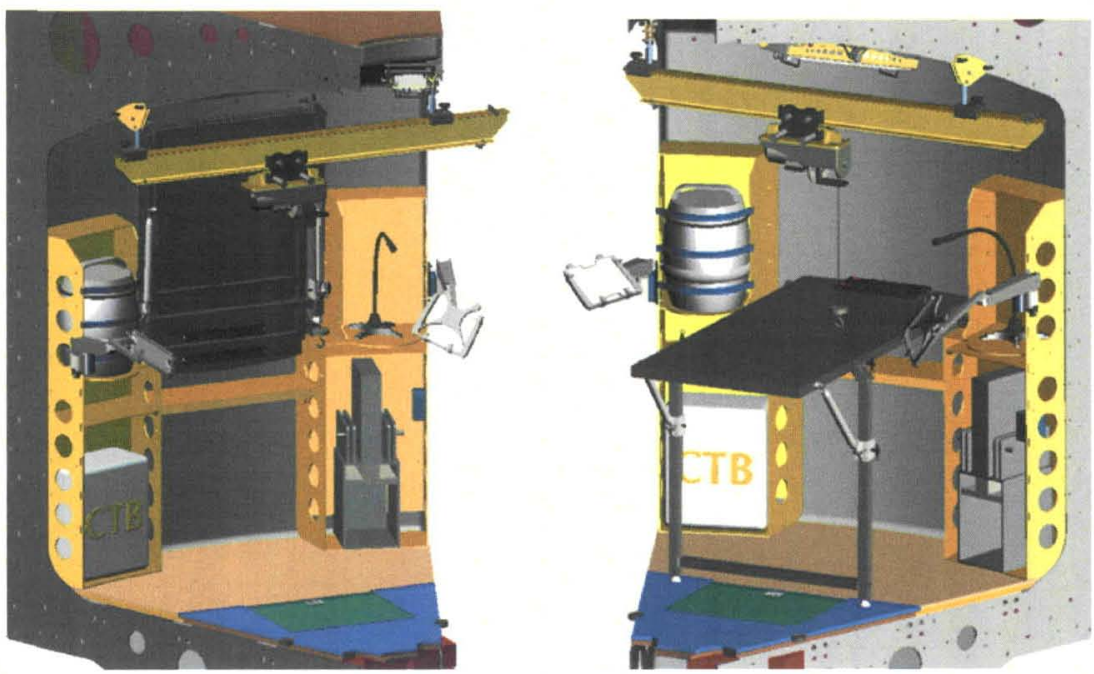

Figure 4 - GMWS Final Design

Equally as complicated was the design of the electric hoist and mount for the GMWS. The requirement was to have an electric hoist capable of hoisting up to $400 \mathrm{lbs}$. Having this capability would enable the crew to hoist objects or parts, for example, from the Space Exploration Vehicle rover onto the GMWS table, where they could then be repaired or have maintenance performed. Even though the requirement of $400 \mathrm{lb}$ was requested, an analysis of the HDU rib loading had to be completed to ensure that if a large load was ever lifted by the electric hoist, the frame of the HDU would not deform or collapse. First, the team obtained a layout of the rib loading from the structural subsystem team. Figure 5 below displays the max loads allowable for the HDU rib.

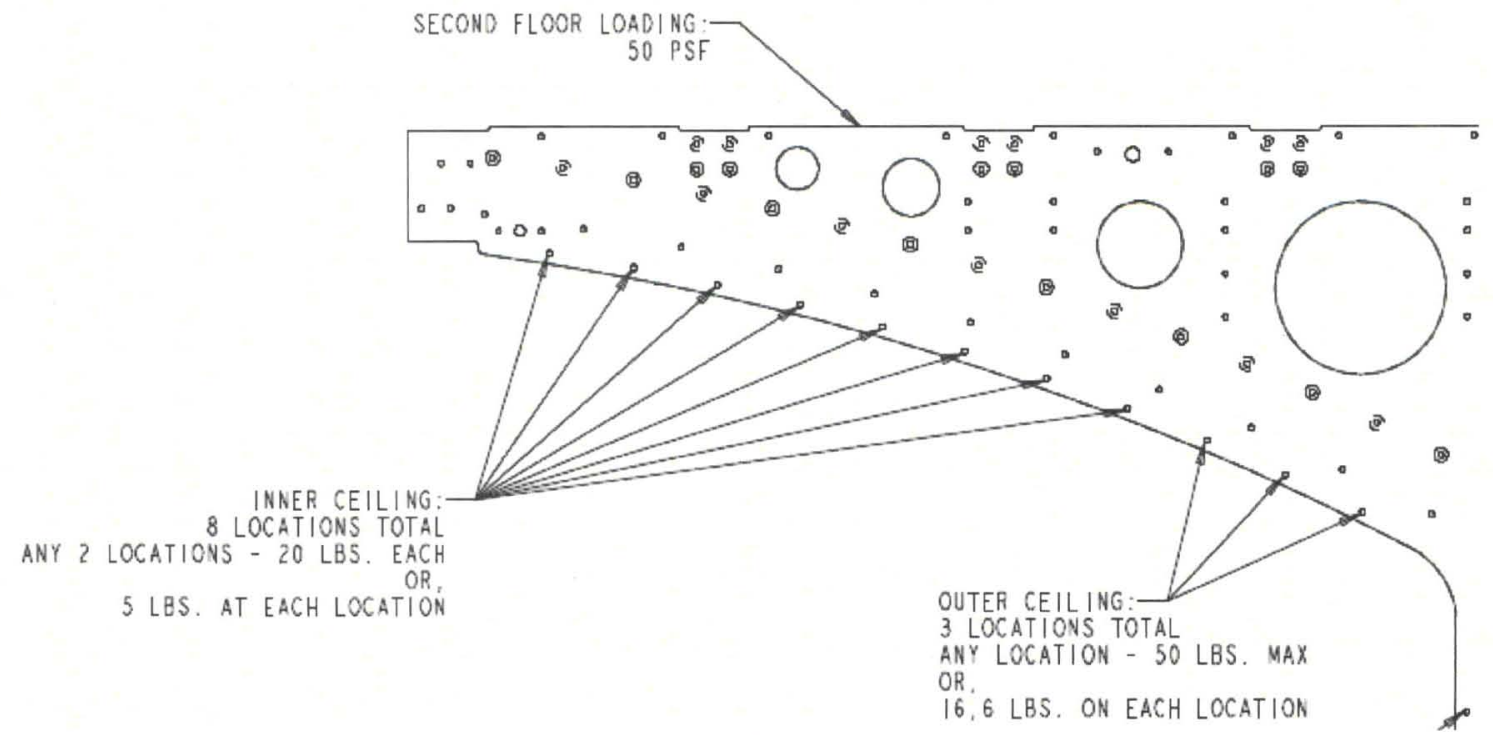

Figure 5- HDU Rib Loading

By using this loading information, the designers were able to perform a load analysis by first assigning material properties to the HDU rib model, then applying a simulated load (seen in Figure 6 below) from the center of the beam that equals the load an electric hoist/trolley assembly would provide. 


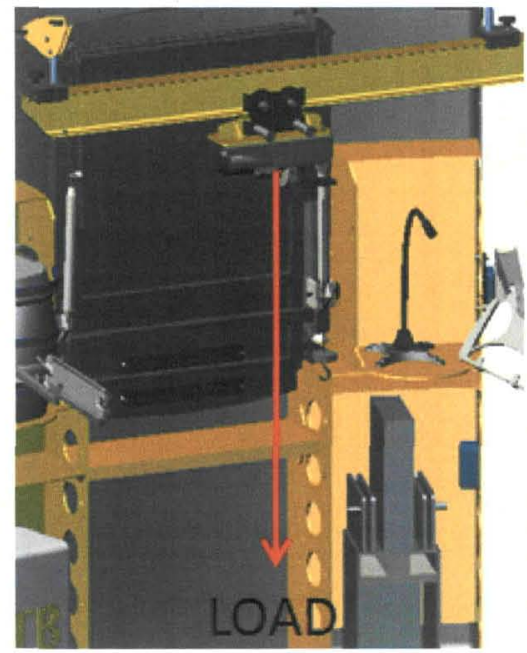

Figure 6 - HDU Hoist Load Point

Once the analysis was complete, the design team determined that instead of attaching the electric hoist mount to one hole on each of the two ribs necessary, the design would require attaching to two points on each rib to avoid any deflection in the rib to get the lifting capacity in the desired range. The original request for the lifting capacity was $400 \mathrm{lb}$, but as it became evident that meeting or exceeding that goal would drive a more unwieldy design, the integrated HDU team agreed to relax the requirement to approximately 200lb. By collaborating with the Langley Research Center designers of the HDU shell, detailed in the next section, using Pro-E, and designing the trolley to attach to two holes and each rib, the GMWS design team was able to maximize the lifting capacity to which the integrated system would be rated. Recognizing that a proof-load test of the integrated assembly would be required at $150 \%$ of the rated capacity once installed at JSC and working backwards from a factor of safety analysis of a 440 $\mathrm{lb}$ load including the hoist and trolley, the GMWS team planned for a proof-load test at $375 \mathrm{lb}$ and rated the lifting capacity at $250 \mathrm{lb}$.

Thus both the conceptual and analytical aspects of utilizing 3-D virtual modeling during the GMWS development facilitated the rapid turnaround from design to delivery of the General Maintenance Work Station from design kickoff in mid-March 2010 to installation of the delivered product in early July 2010 . The delivered product of the GMWS is depicted below in Figure 7 installed in the HDU shell.
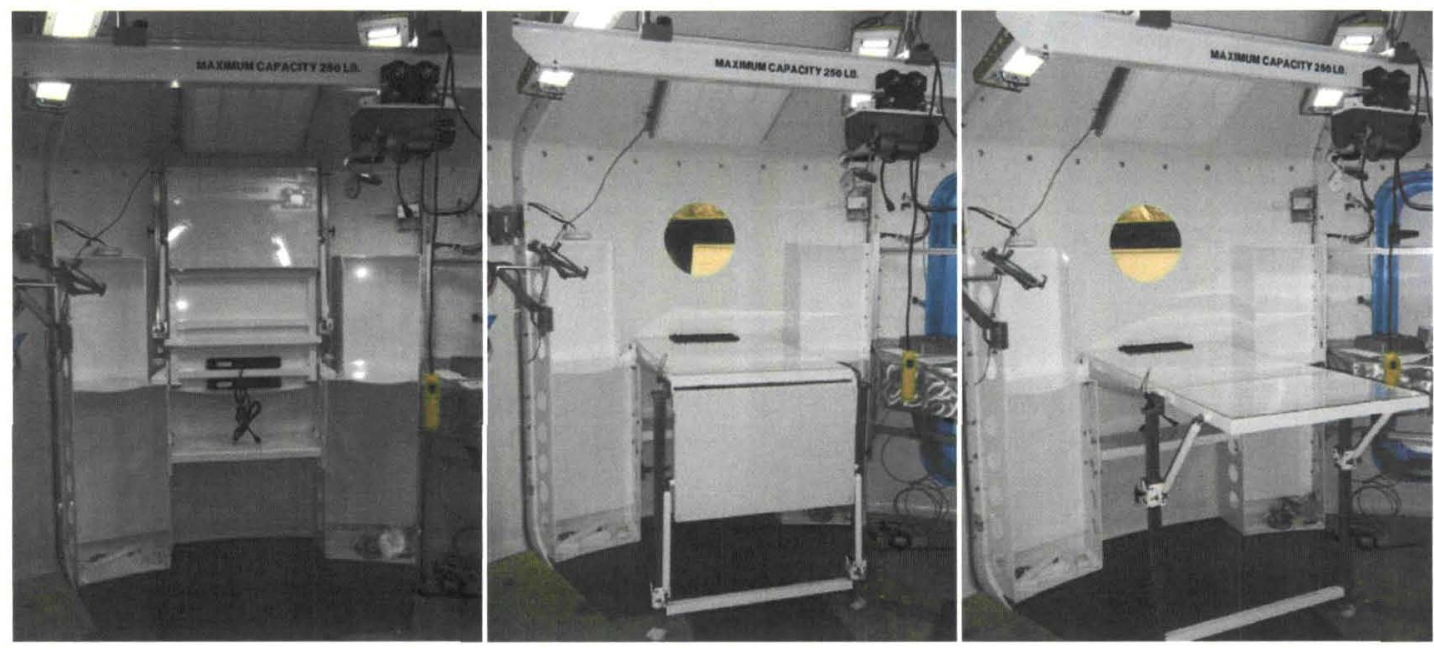

Figure 7 - General Maintenance Work Station installed in HDU 


\section{Shell Manufacturing and Integration Process}

The HDU shell was manufactured in eight shell slices at Langley Research Center. Those slices were shipped to the Johnson Space Center in two shipments, one in December 2009 and the other in January 2010, for assembly and then outfitting with the various PEM systems for the 2010 Desert RaTS campaign. The original concept was to manufacture all the slices and then ship to JSC for assembly prior to installing any system hardware. Early planning schedules showed that the team might begin integration of the hardware within the shell sections before the shell was complete, but the shell manufacturing team was so successful that the shell was fully assembled and ready for integration in late February 2010 at the time systems were starting to become ready for installation.

The HDU shell slices are a composite structure and each of the slices has a steel rib on either end to attach it to the next slice. Thus there is a double steel rib at the joint of each slice to slice interface. The shell slices are made from one common mold that is modified for the variations of a smooth slice or a slice with a door opening. The smooth slices also include one slice that has a window opening and thus requires a slight modification to the mold. To minimize down time in modifying the mold, the HDU team optimized the production by making several smooth slices and then the slices with door openings and the one with a window. Examples of an HDU rib and the mold for the shell slices are seen below in Figure 8.
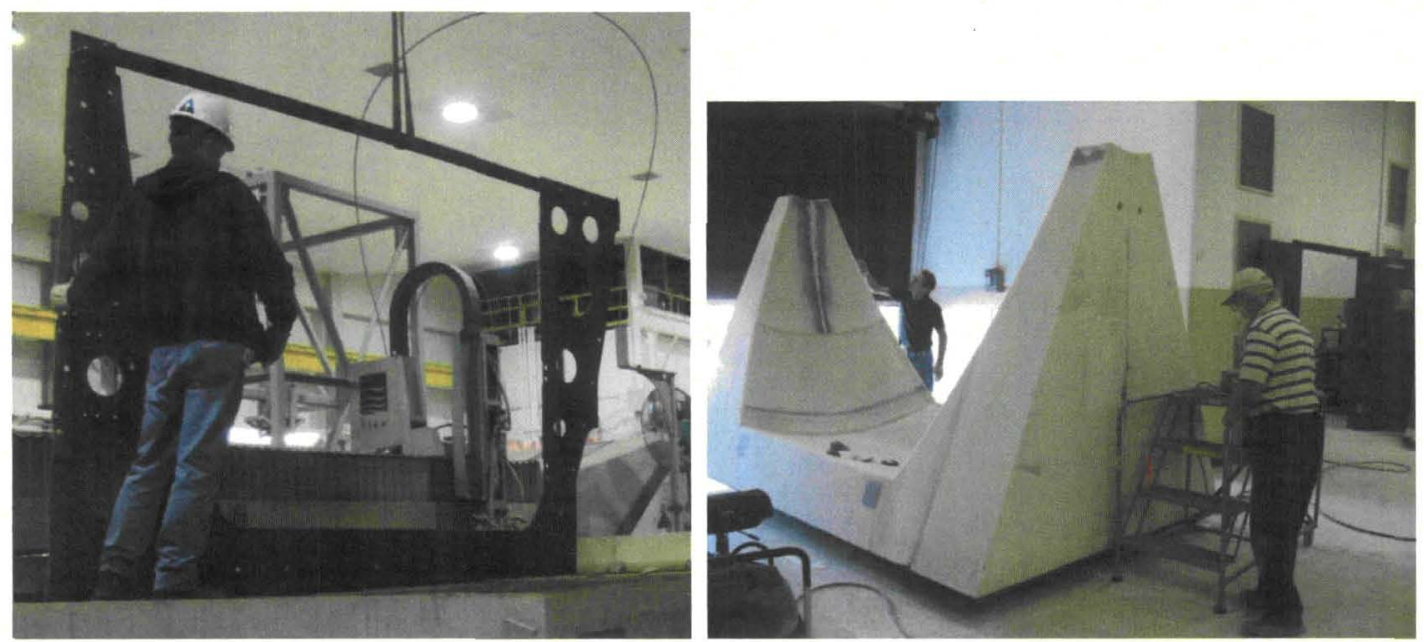

Figure 8 - An HDU Rib being removed from the water-jet machine (left) and the HDU shell slice mold during its fabrication (right)

The shell sections were designated for hardware installation per the proposed layout of HDU PEM Systems as seen in Figure 9 - HDU PEM Layout. This layout reflects the original two dimensional layout plan which was greatly enhanced by the three dimensional CAD model. 


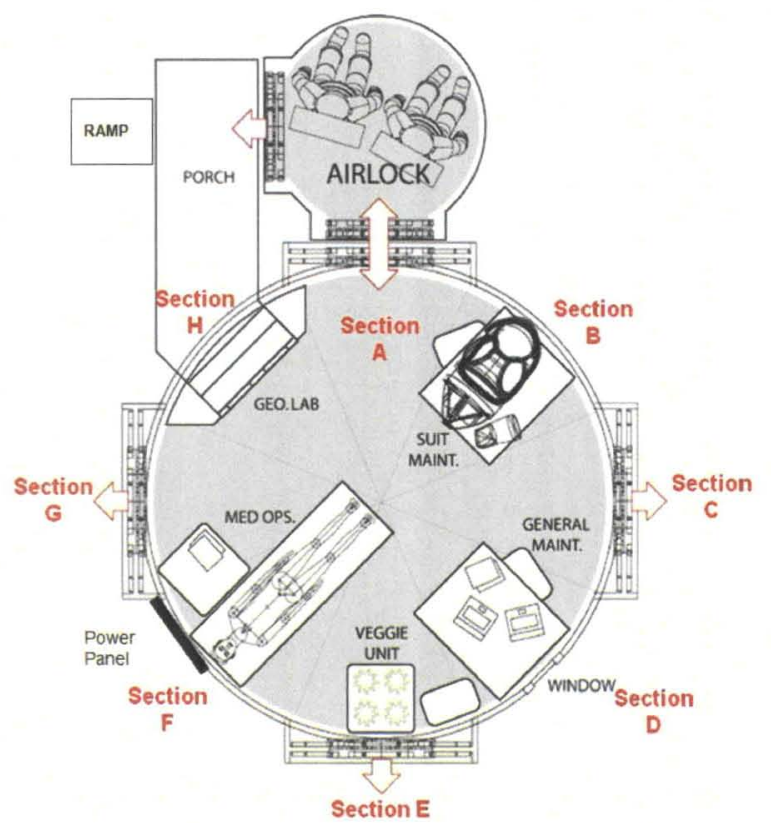

Figure 9 - HDU Pressurized Excursion Module Layout

The layout consists of four quadrants with the General Maintenance Work Station, the Extravehicular Suit Maintenance area, a Medical Operations workstation, and a Geology Laboratory (Geo-Lab) area. In addition to the layout of the four quadrants, the installation of all the support systems such as avionics, thermal, lighting, communications, and environmental sensors had to be planned. Towards that end, a matrixed mapping of the systems to the shell slices was made, and this mapping was used as one of the foundations for integration schedule development (displayed in Table 1).

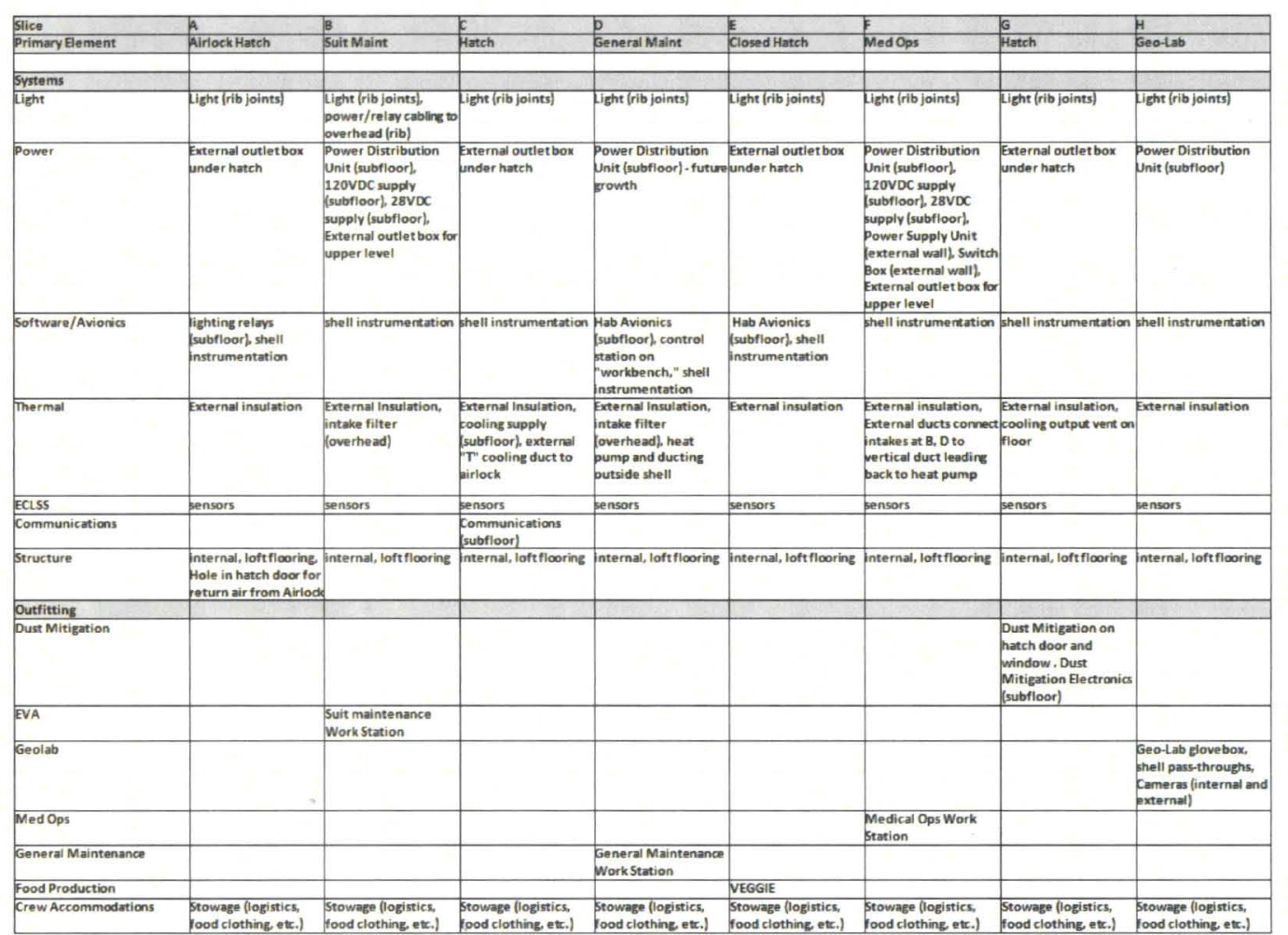

Table 1- HDU Pressurized Excursion Module Slice Layout Matrix 
The other main factor in schedule development was a system by system installation progression where followon systems depended on earlier ones, such as power, for their operation. The virtual representation of the HDUPEM layout, used during the integration process, from the CAD integration activities is pictured in Figure 10.
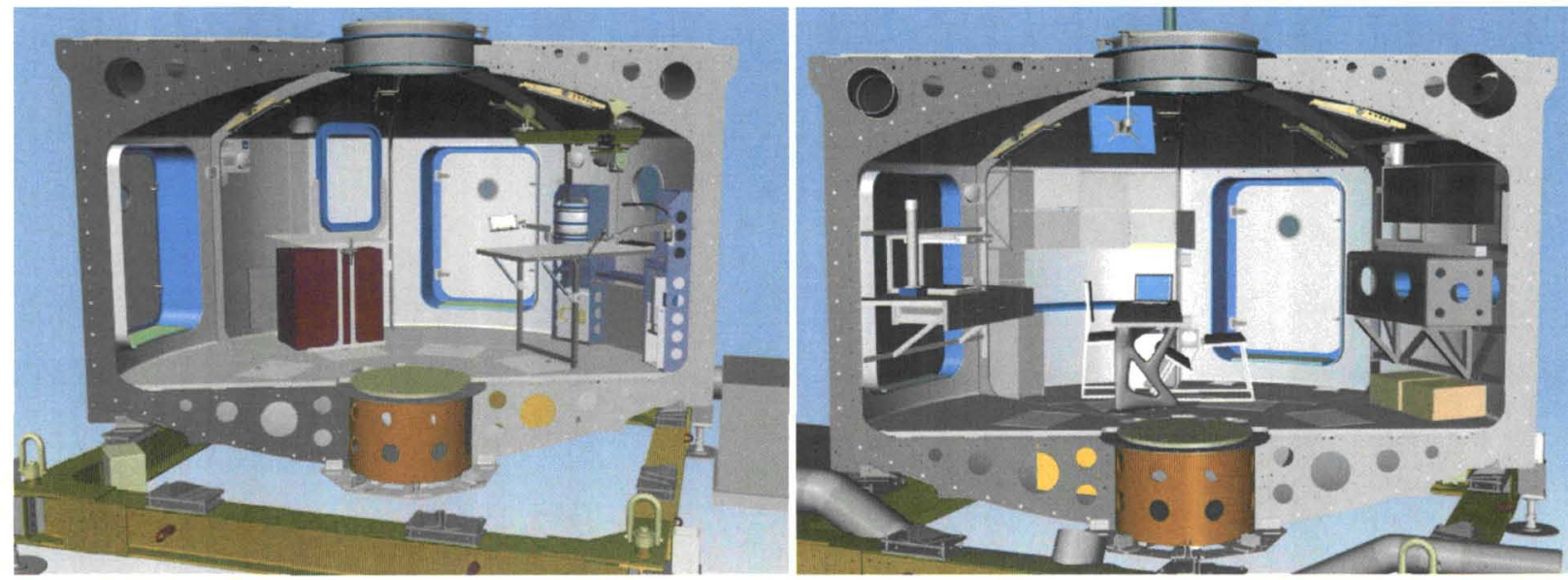

Figure 10 - Virtual Representation of HDU layout in Sections A-D (left) and E-H (right) in modeling tool

Integration tasks require a lot of coordination among the integration team and hardware developers, so the schedule was constantly maintained and updated using Microsoft Project to optimize the limited time available for integration and test prior to deployment for dry runs and Desert RATS. Some of the more challenging tasks during the actual integration phase were the application of foam insulation and the installation, wiring of subsystems underneath the floor level of the HDU, and the modification of an existing airlock simulator to work with the HDUPEM. Various scenes during the actual HDU-PEM integration from February - March 2010 can be seen below in Figure 11.
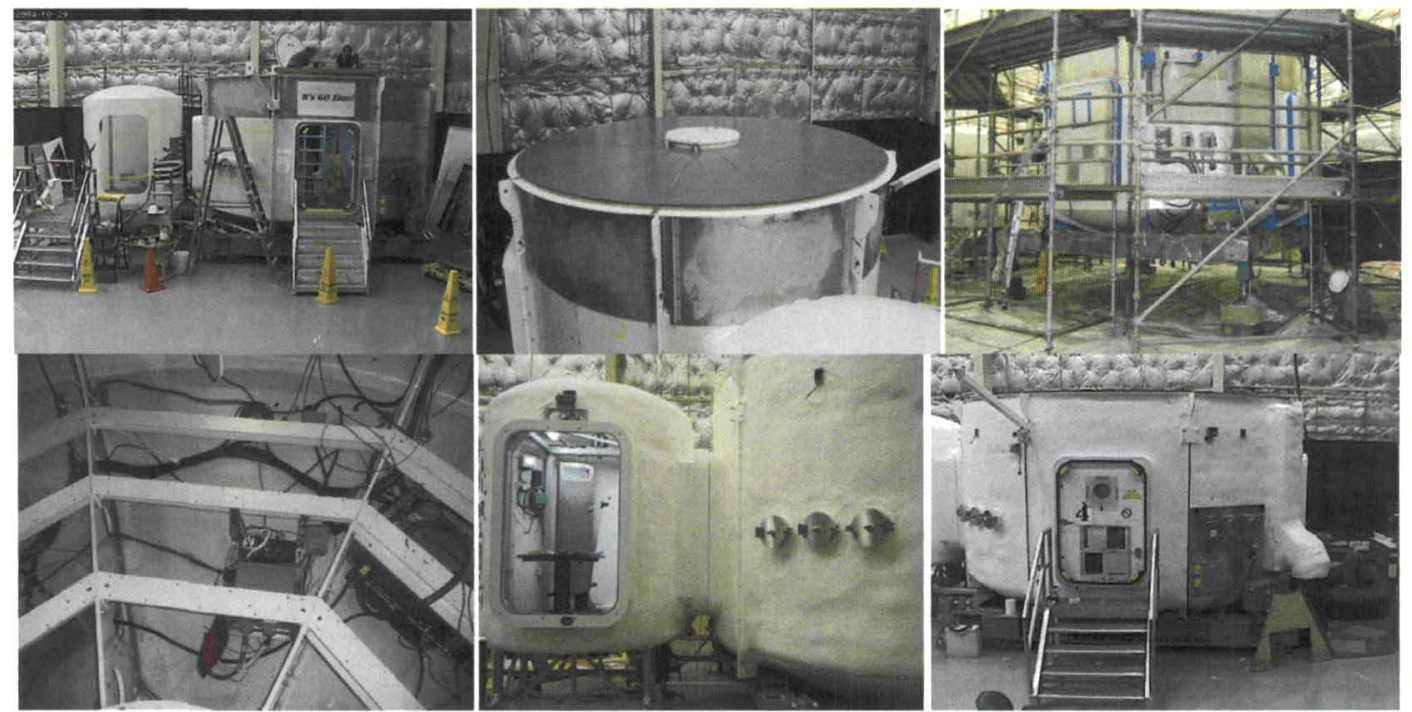

Figure 11 - Scenes during HDU-PEM integration

The HDU project performed a trade analysis to select a preferred transportation configuration. The HDU project is planning on 1 or 2 transport round trips per year. The transportation configuration was important in deriving the HDU shell design and manufacturing requirements. An HDU shell design and manufacturing requirements document was developed to ensure the HDU shell would meet the project expectations and requirements. The transportability trade assessed three options of 1) transporting the HDU as a fully assembled unit, 2) transporting the HDU as a single-split unit configuration, and 3) transporting the HDU as a dual-split unit. Each configuration 
affected the design and manufacturing of the shell. Evaluation criteria were defined, and an evaluation matrix was developed for the analysis.

The assessment determined that the cost for manufacturing a more complex split configuration shell, its in-field assembly, special transport support equipment and coverings, additional ground support equipment, and added risks out-weighed the cost of transporting a super-size load. The benefits of shipping an integrated HDU as a super-size load were great enough to overcome that fact that a super-size load is about 10 times more costly than a standard tractor trailer load.

The decision outcome of the trade study was to manufacture the shell in the "orange slice" mold approach, to ship in sections, quarter panels or fully-assembled to JSC, to integrate subsystems at JSC, and to transport to the field analog site as a fully integrated unit - not in a split and disassembled configuration.

Furthermore, a transportation cradle has been designed to support three purposes for the HDU: (1) integration and test at Johnson Space Center, (2) transportation to field locations, to other centers, or to outreach activities, and (3) field operations in the desert analog locations. For field operations, the cradle will allow a flatbed trailer to transport the HDU as an analog substitute for the All-Terrain Hex-Legged Extra-Terrestrial Explorer (ATHLETE) rover depicted in the Figure 1 lunar architecture concept. The cradle, pictured in Figure 12, was delivered by LaRC with the HDU shell to JSC in Jan 2010. While in the field, the HDU will be transported on a flatbed trailer to its deployment locations, supported by this cradle. Additionally, this cradle was fitted with heavy duty jack stands for adjustment of the height and leveling to be able to configure for docking with the SEV rover in the Desert RaTS and dry run trials.

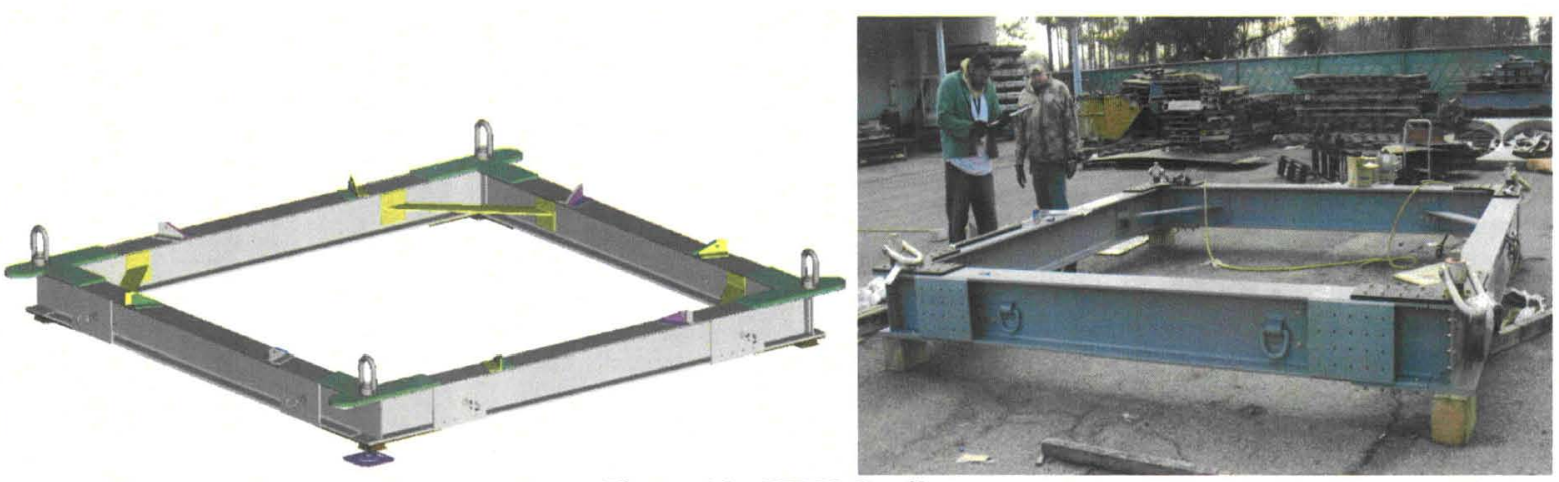

Figure 12 - HDU Cradle

\section{Test Operations}

A series of test operations for the HDU-PEM systems was designed to prepare the team, the hardware and software systems, and the procedure for the eventual Desert RATS activities. The testing was broken into three main phases beginning in July 2010, when the system was deemed ready to "rollout," and procedure development was built to facilitate the success of those phases. An HDU-PEM Operations Manual with background on every system, procedures required for each system, and scripted scenarios required for field activities. The Operations Manual procedures were developed for use on all three phases of testing, and a time-lined plan of activities utilizing the Operations Manual procedures was developed for each test phase. This way, each test would refine the Operations Manual Procedures for follow on tests and not drive separate procedure development efforts. The first phase was a suite of integrated systems tests where the various systems were powered on sequentially to collect data on power consumption, bandwidth consumption, and RF spectrum characterization. Additionally, some scripted test activities to support field testing were practiced such as the activation and deactivation sequences, the emergency shutdown sequence, and the transitions between active and quiescent modes. The next phase between mid July and early August 2010 was a period of dry run tests performed at the Johnson Space Center Rock Yard where lunar and Martian surface simulations are employed. These Rock Yard tests allowed the team to exercise procedures not only for system testing but for loading, transportation, unloading, and setup. The tests also engaged the Space Exploration Vehicle rovers, and all procedures intended to be run at the Desert RATS 2010 campaign were first executed at the Rock Yard. Finally, the culmination of the efforts is planned for the Desert RATS 2010 campaign from late August to mid-September 2010, highlighted by a two week traverse of the SEV rovers and two dockings of the rovers to HDU for integrated science activities. 


\section{Conclusion}

The Habitat Demonstration Unit project is constructing a habitat shell to act as a test bed for instances of a habitation architecture. For 2010, the instance represented by the HDU will be the Pressurized Excursion Module of the lunar architecture, and it will be put to test in the 2010 NASA Desert Research and Technology Studies (RaTS) campaign as depicted in CAD in Figure 13 and in photos in Figure 14. Significant challenges to accelerate from a project start to a field deployment in just over a year are being addressed with several facets of the HDU integration strategy. Significant effort is being made to define and document standards for system integration which will be valuable for not only the PEM but future versions of the HDU. Additionally, the HDU project has planned scheduled activities including the use of computer aided design in the layout of systems, the use of fit-check opportunities, and the utilization of a Habitat Test-bed avionics platform to mitigate the risk of integration the systems together for the first time within the HDU. Finally, the entire concept of operations from the planning of the manufacturing, shipment, and integration to the field operations have all been factored into the design of the HDU to streamline the integration activities allowing the project team to meet the ambitious timeline for deployment of a PEM for Desert RaTS 2010.

Looking forward, during fiscal year 2011, the HDU will evolve as a Habitat-Laboratory combination featuring an inflatable loft provided through the X-Hab Challenge. For more details on the X-Hab challenge, reference http://www.spacegrant.org/xhab/. The same integration strategies discussed in this paper will be applied during FY11 to enable the utilization of the HDU as a platform for exploration architecture validation.
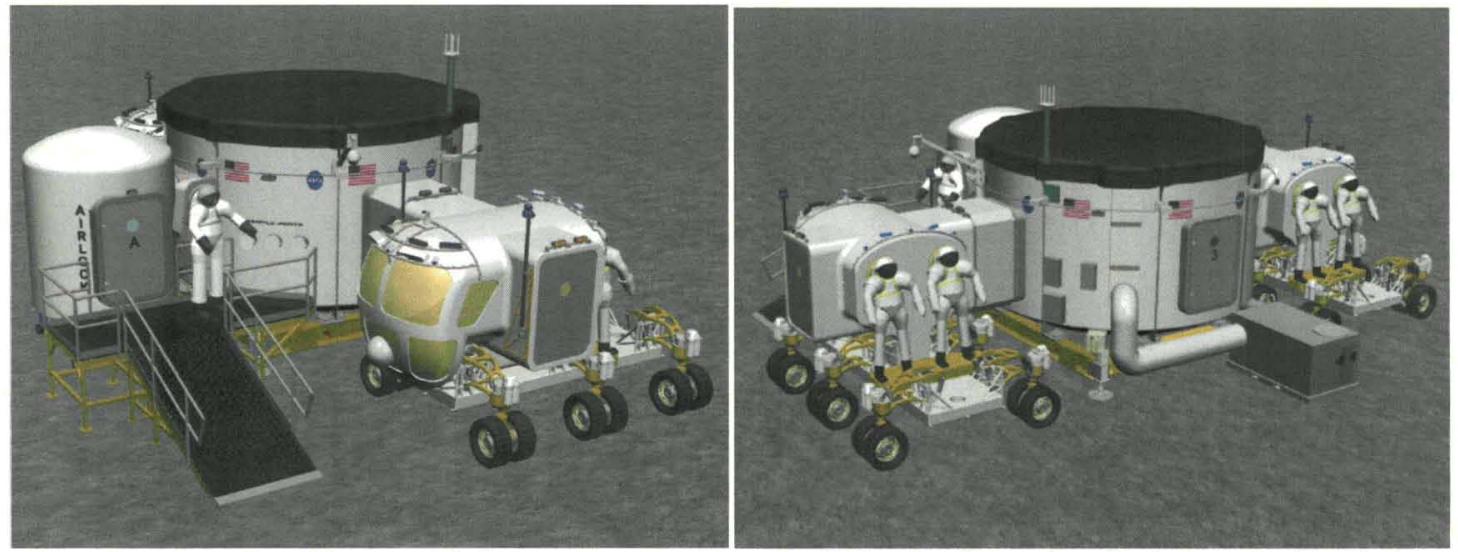

Figure 13 - CAD of Assembled HDU Mounted on Cradle in Configuration for Desert RaTS 2010
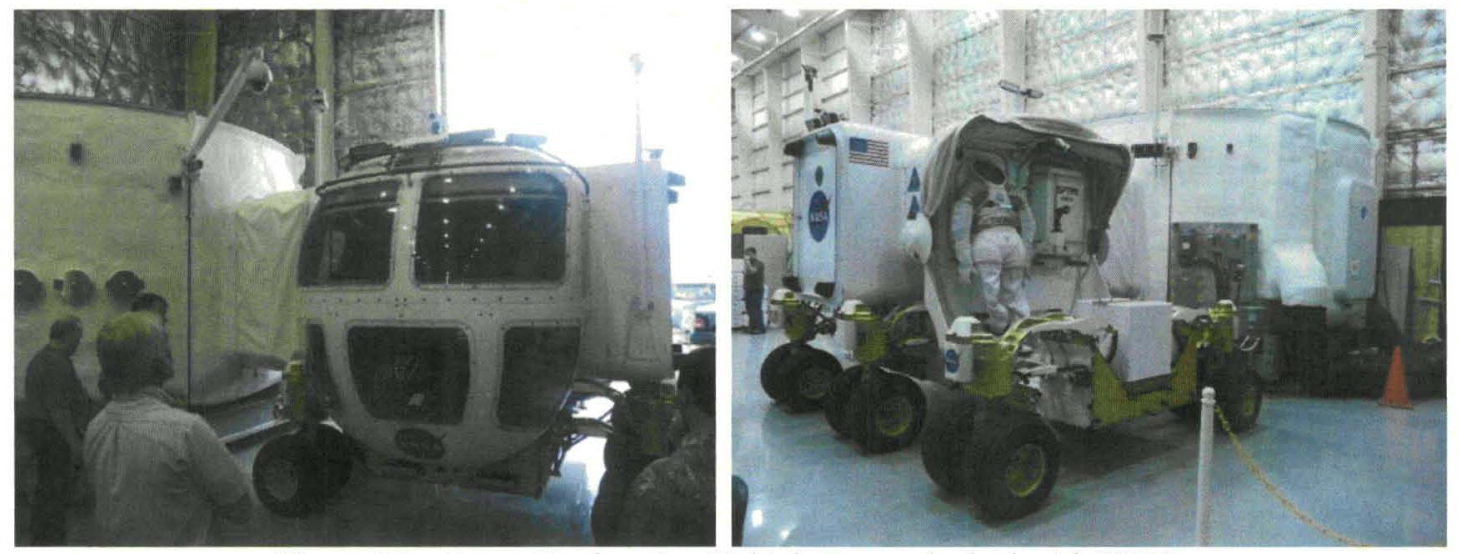

Figure 14 - Space Exploration Vehicle Rover docked with HDU. 


\section{Habitat Demonstration Unit Project Systems Integration}

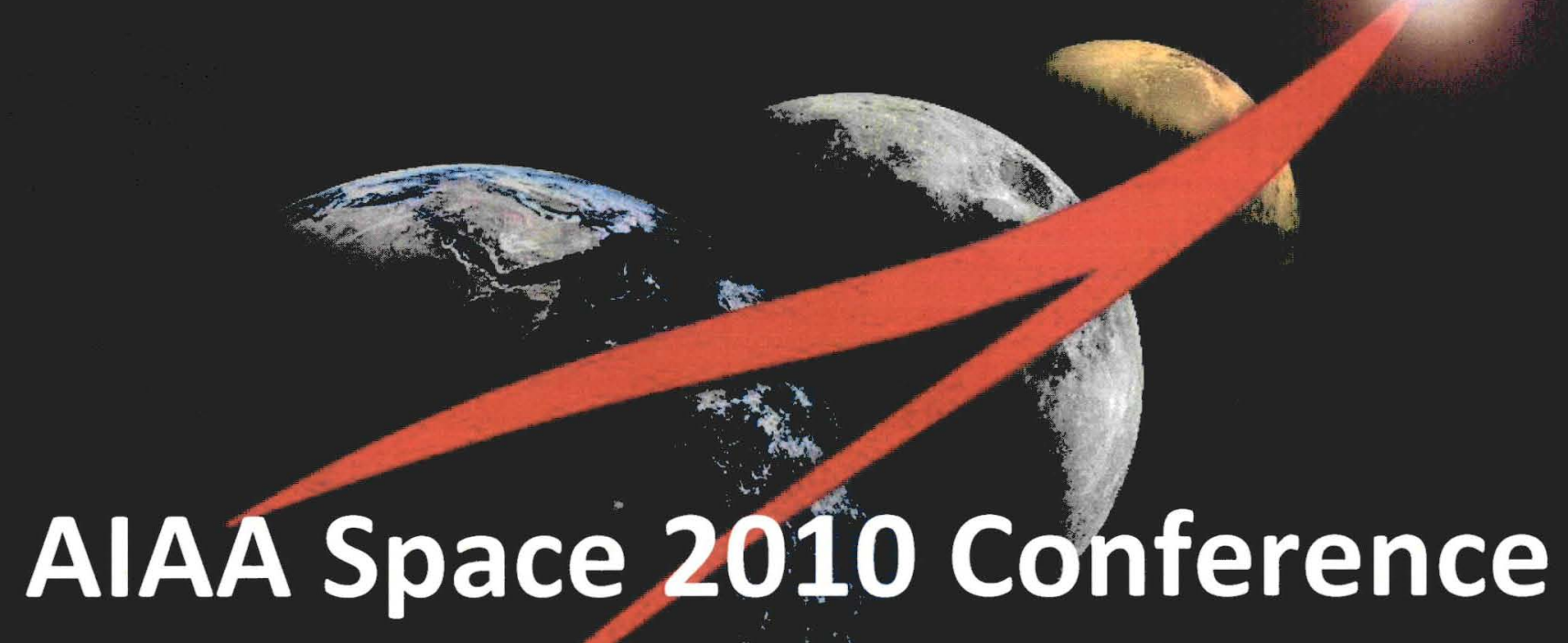

Anaheim, California

Aug 30 - Sep 2, 2010

T.R. Gill, J.C. Merbitz, K. J. Kennedy,

T. O. Tri, and A. S. Howe

NASA HDU Project Team 


\section{HDU Project Team}

- NASA centers participating in HDU Project: JSC, KSC, JPL, LaRC, GRC, \& ARC.

- HDU Management Team: Kriss Kennedy/JSC, Project Manager; Design Integration Lead, Scott Howe; System Integration Lead, Tracy Gill/KSC; Terry Tri, Test Operations Lead; Larry Toups/JSC, LSS Habitation Lead; \& Amanda Lynch/JSC, Project Integration

- Systems Leads: Scott Howe, Airlock; Robert Howard, Human Factors; Jerad Merbitz, Lighting/General Maintenance Work Station; Rick Scheuring, Medical Systems; Robert Trevino \& Natalie Mary, EVA Systems; Amanda Carpenter, SE\&l; John Dorsey \& Tom Jones, Structures and Mechanisms; John Cornwell, Active Thermal Control; Joe Chambliss, Life Support; Gregg Hall, Avionics; Pat George, PM\&D; Danny Carrejo, Habitat Test-bed; Ed Walsh, Assembly Integration; Dennis Lawler, Software \& Avionics; Marc Seibert, Communications; Jim Broyan, Crew Accommodations; Sandy Wagner, Dust Protection; Cindy Evans \& Michael Calaway, Geo-Science Lab; Ray Wheeler, Food Production 


\section{Agenda}

- Background

Integration Strategy

- Design Standards

Risk Mitigation

Shell Manufacturing and Integration operations

Test Operations

- Conclusion 


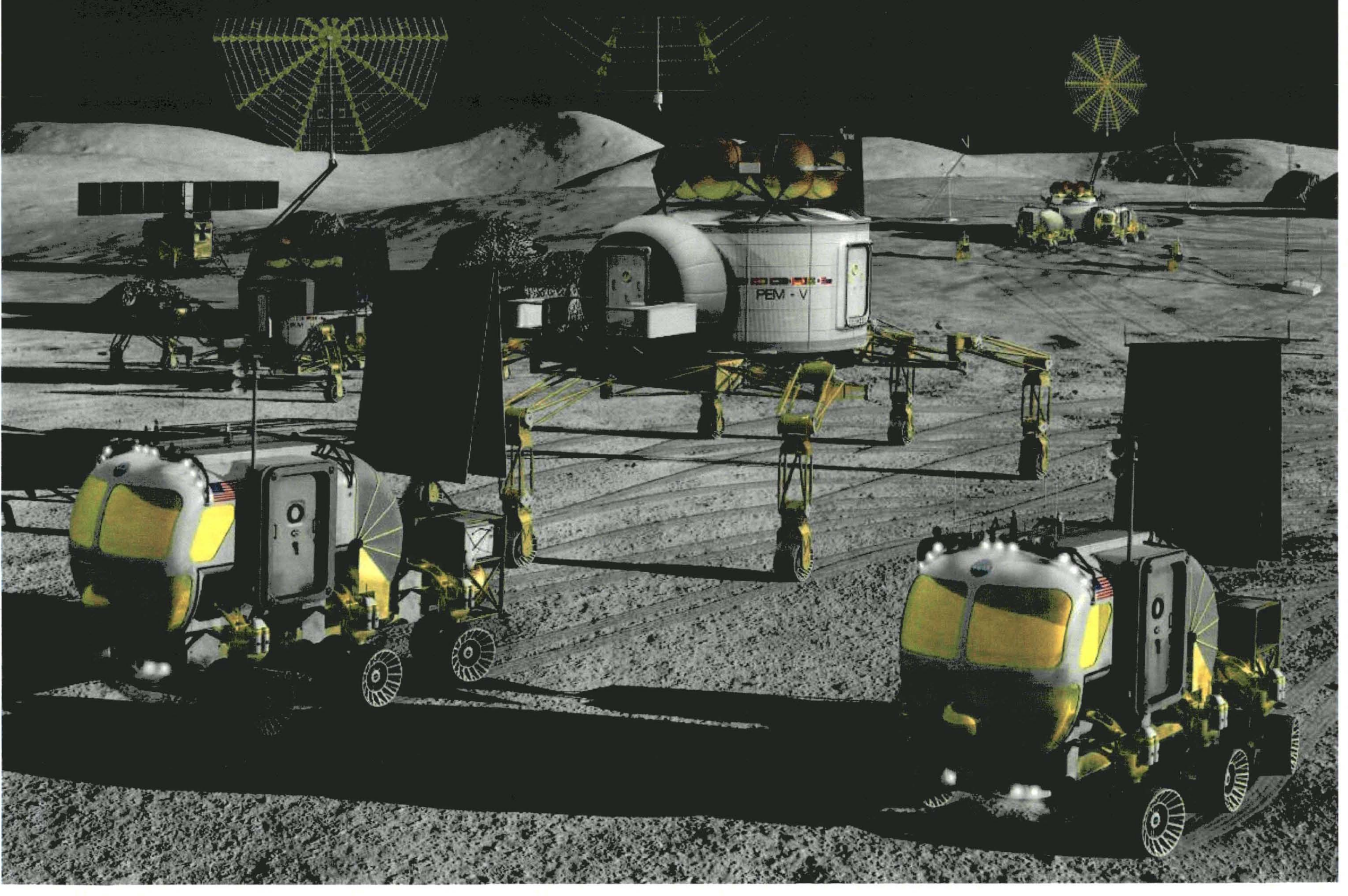




\section{HDU-PEM Systems Integration Background}

- A technique being utilized in NASA's lunar architecture analysis is analog testing of the lunar environment in desert locales.

- "Day in the life" scenarios at a lunar outpost with prototype equipment allows designers insight into the utilization of the proposed systems and refines architecture and operations concepts.

- A series of Desert Research and Technology Studies (RaTS) have been held in locations such as Moses Lake, Washington and Black Point Lava Flow, Arizona

- Most recent test in September 2009 was performed with a Lunar Electric Rover, and a fourteen day excursion was practiced.

- The $\mathbf{2 0 1 0}$ session of Desert RaTS is planned for Black Point Lava Flow where two LERs will operate together and this lunar habitat prototype, the Habitat Demonstration Unit to the two LERs to allow for a 14-21 day simulated mission.

- The Pressurized Excursion Module (PEM) will be represented by the HDU in 2010. One difference in the version of the PEM depicted in that figure from the HDU version of the PEM is that the HDU version will allow for a second story loft rather than accommodate commodity storage tanks on its roof.

- The PEM function is to provide a mobile facility in which to provide research and habitation functionality in a mobile outpost concept. 


\section{HDU1-PEM Configuration}

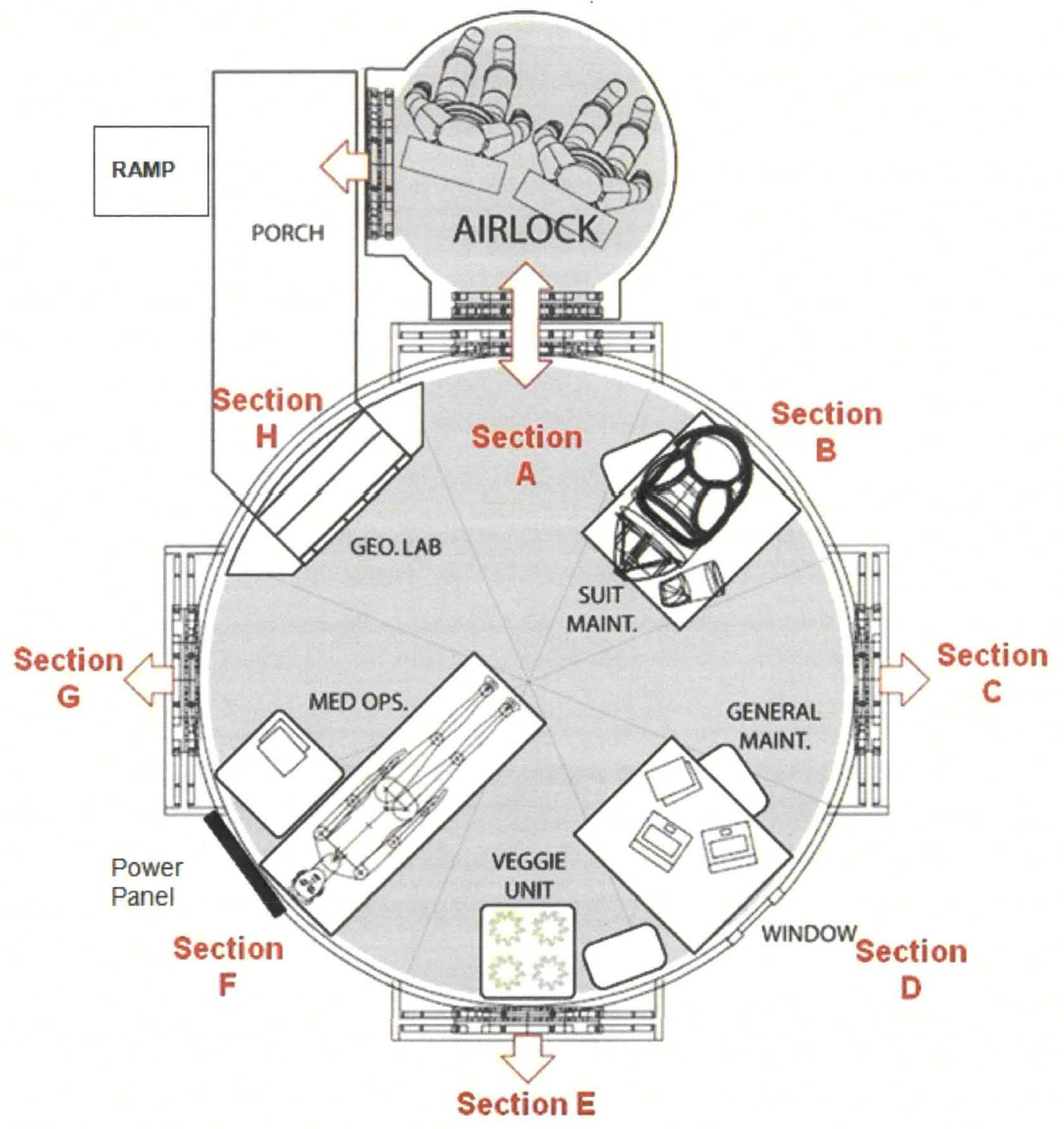




\section{HDU Integration Strategy}

- The HDU team chose to utilize convenient design standards to facilitate manufacturing and integration

- Utilized common molds for the hatches used for Lunar Electric Rover

- Defined common standards for core subsystems to simplify the addition of other systems later (120VAC, common bolt hole patterns on ribs)

HDU team used several approaches for risk mitigation to buy down risk prior to installing systems in the shell

- Scheduled Activities

- Mechanical fit check opportunities

- Utilization of Habitat Testbed for software and model validation prior to utilization for system testing

- Utilization of Habitat Testbed as bench-top platform for early systems tests prior to the final installation of those systems into the HDU shell

- Utilization of Master Equipment List to track planned installations

- Tracking of scheduled activities in comprehensive Microsoft Project schedule

- Modeling and simulation tools used for Integration Analysis

- Coordinate System for the shell sections and elevation from floor level

- Used for layout of subsystems and evaluation of sizing, cable lengths, and operational issues prior to physical integration (see next chart) 


\section{Hi⿱亠乂 \\ Utilization of Modeling and Simulation Tools for Integration Analysis}
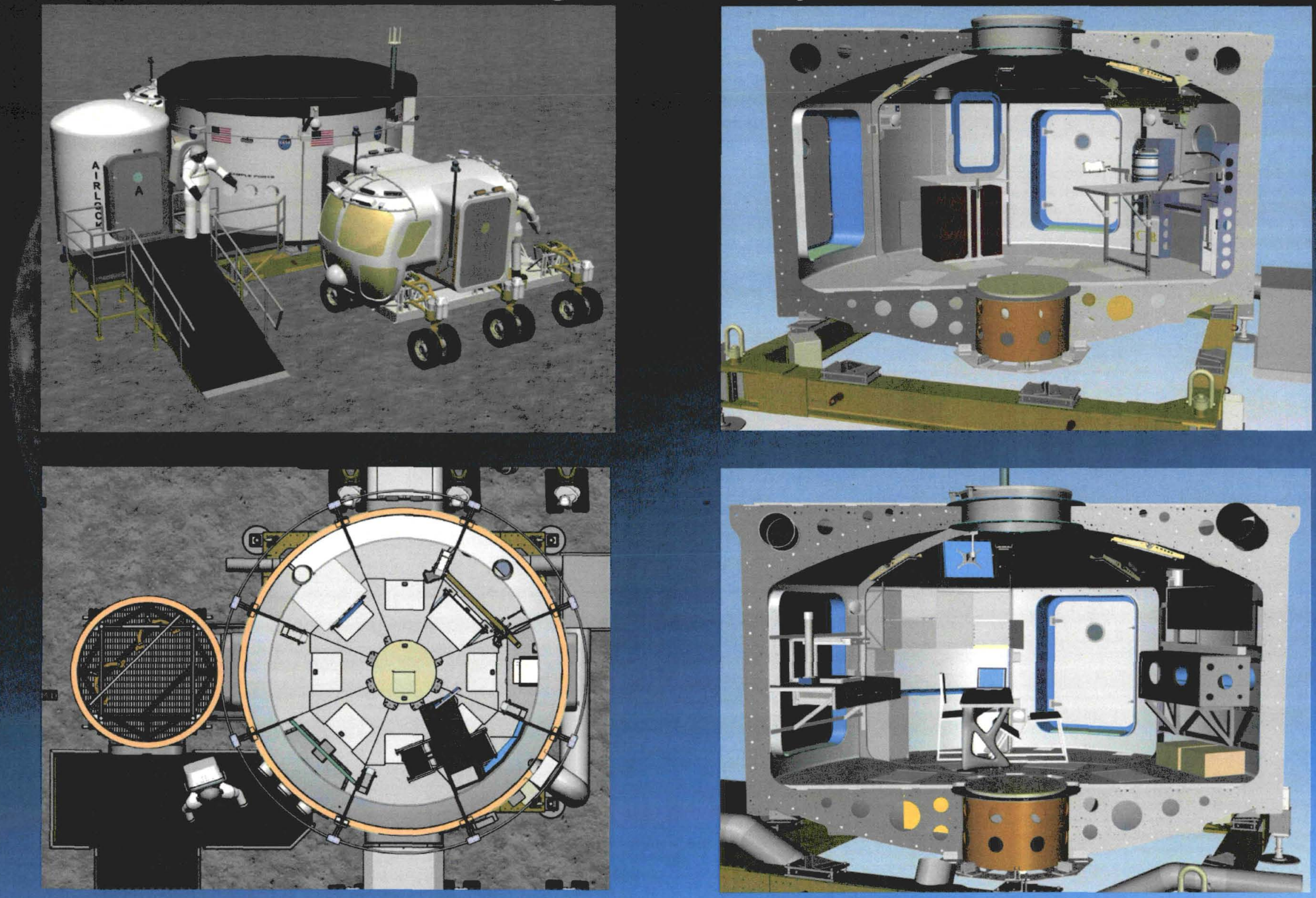


\section{HDU Shell Manufacturing}

- The HDU shell, designed by Langley Research Center engineering, consists of 8 slices of composite structure. Each slice has a steel rib on either end to attach it to the next slice. Thus there is a double steel rib at the joint of each slice to slice interface.

- The shell slices are made from one common mold to simplify manufacturing that is modified for the variations of a smooth slice or a slice with a door opening. The smooth slices also include one slice that has a window opening and thus required a slight modification to the mold. The final slice was a split mold custom fitted in place to complete the shell.

- These individual slices also facilitated simple transportation from LaRC to JSC where final assembly of the shell occurred in two deliveries in December 2009 and January 2010.

HDU rib lifted from water jet machine

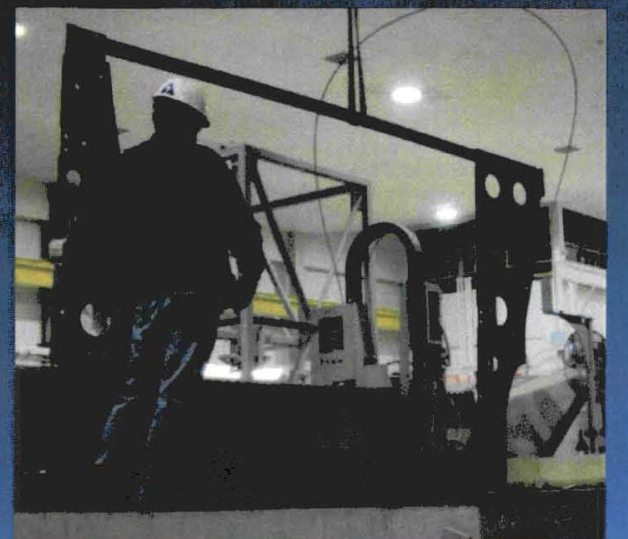

HDU slice mold

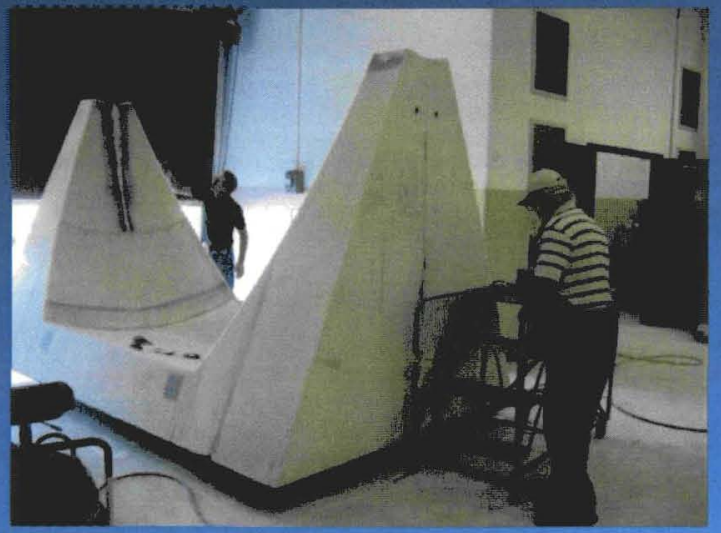

HDU rib assembly pedestal

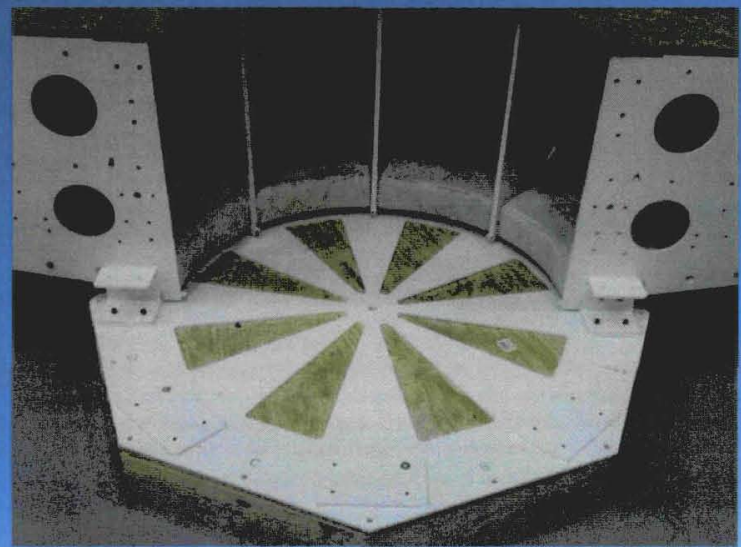




\section{Operations Concept Effects}

- A trade study assessment was performed to select a preferred transportation method for HDU for 3 configurations that affected the design and manufacturing of the shell

- The assessment determined that the cost for manufacturing a more complex split configuration shell, its in-field assembly, special transport support equipment and coverings, additional ground support equipment, and added risks out-weighed the cost of transporting a super-size load. The benefits of shipping an integrated HDU as a super-size load were great enough to overcome that fact that a super-size load is about 10 times more costly than a standard tractor trailer load.

- Factoring in integration operations at JSC as well as field operations in desert locations led the team to design a multi-purpose cradle for integration, transportation, and field operations

First four slices assembled Dec 2009

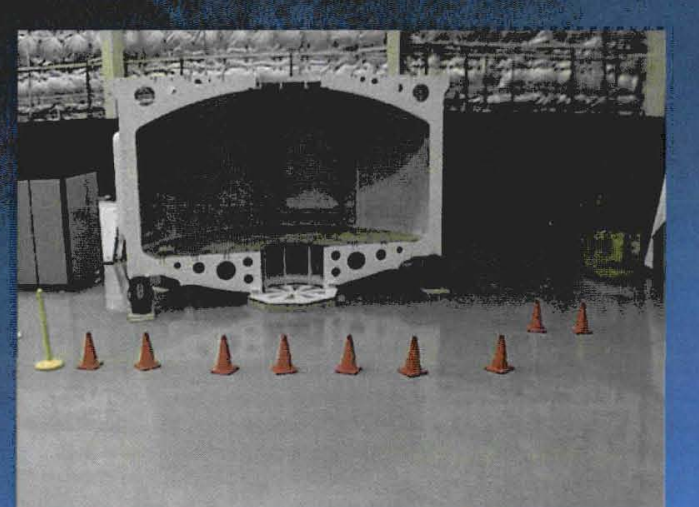

HDU cradle

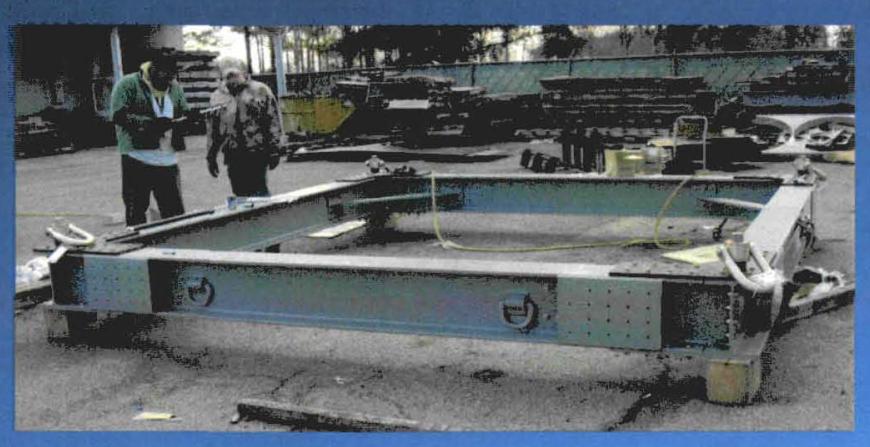

Shell assembly complete Feb 2010

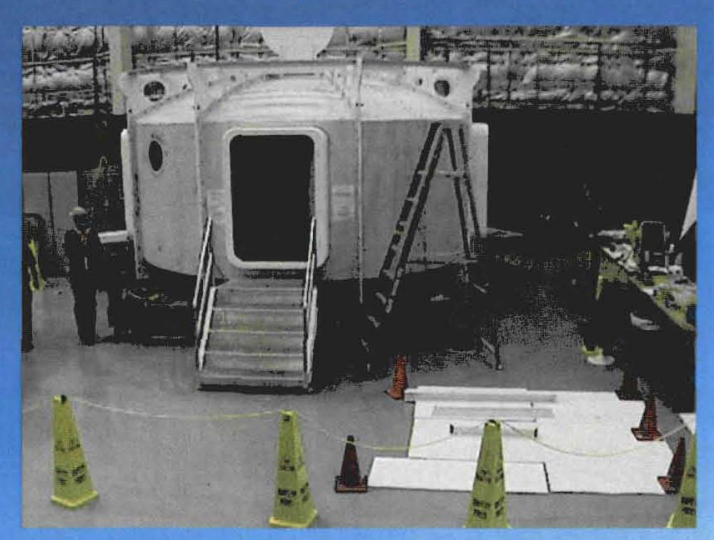




\section{HDU Systems Integration}

- Integration tasks require a lot of coordination among the integration team and hardware developers, so the schedule was constantly maintained and updated using Microsoft Project to optimize the limited time available for integration and test prior to deployment for dry runs and Desert RATS.

- An integrated set of schematics was developed using AutoCAD to both plan the wiring of the systems and to reflect wiring updates made during installation operations

- Some of the more challenging tasks during the actual integration phase include the following:

- the application of foam insulation and the installation

- wiring of subsystems underneath the floor level of the HDU

- the modification of an existing airlock simulator to work with the HDU-PEM.

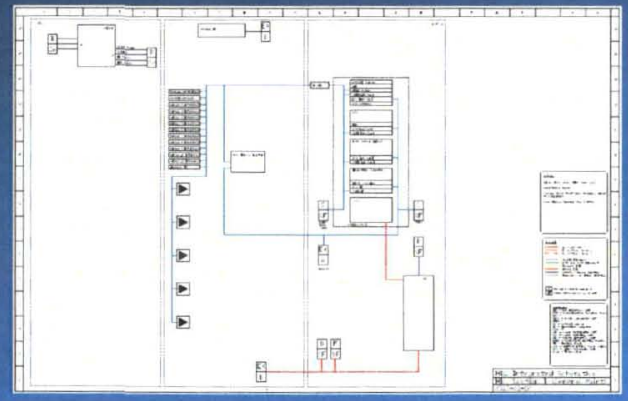

Integrated Schematics Sample 


\section{HDU Systems Integration}

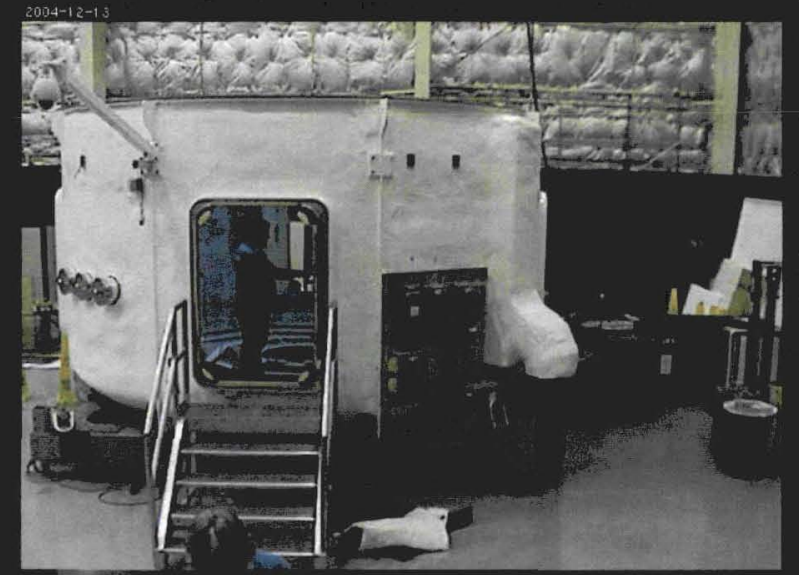

Glovebox External Sample Ports and Camera, Power Panel, Heat Pump Integration

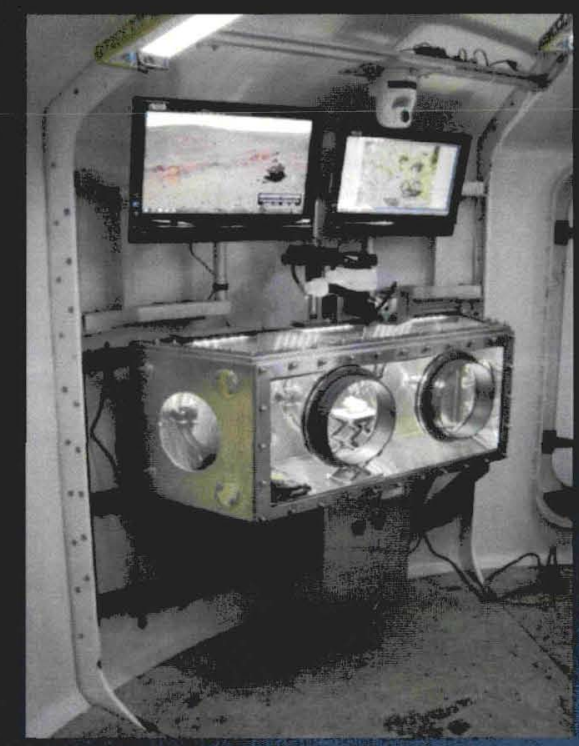

Geo-Lab Glovebox with Monitors and Internal Camera

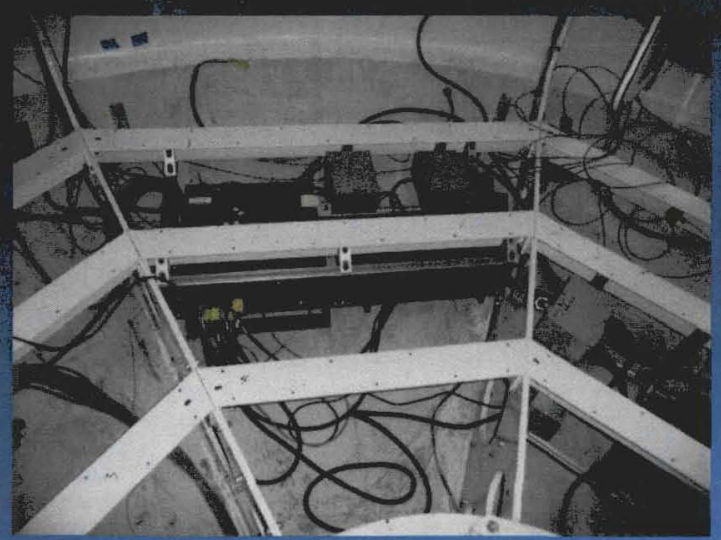

120 VAC PDUs, 120VDC and 28VDC Power Supplies in Sub-Floor

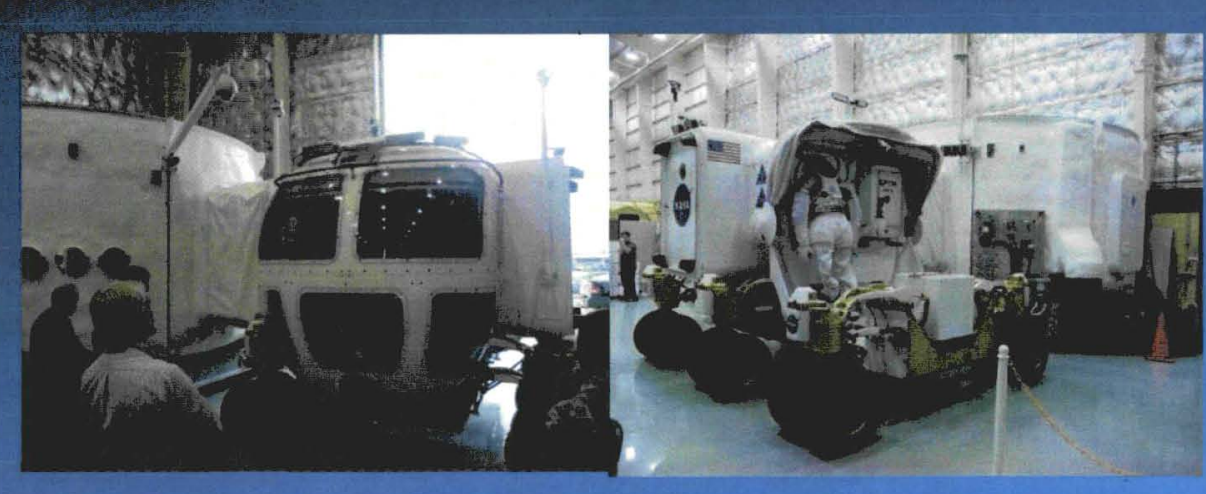

Space Exploration Vehicle Rover Docking to HDU

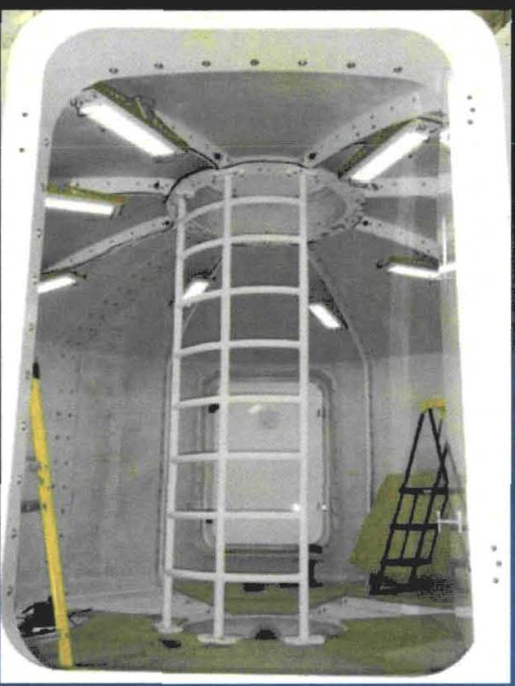

HDU Internal Solid State Lighting

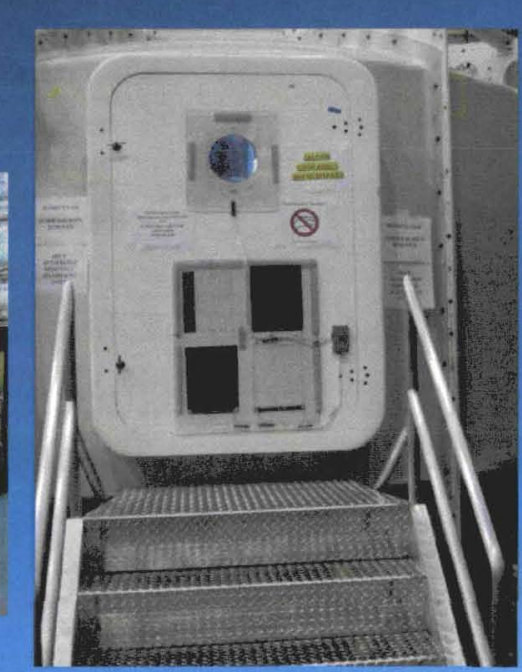

Dust Mitigation - Electrostatic Dust Shield and Lotus Coating 


\section{HDU Systems Integration}

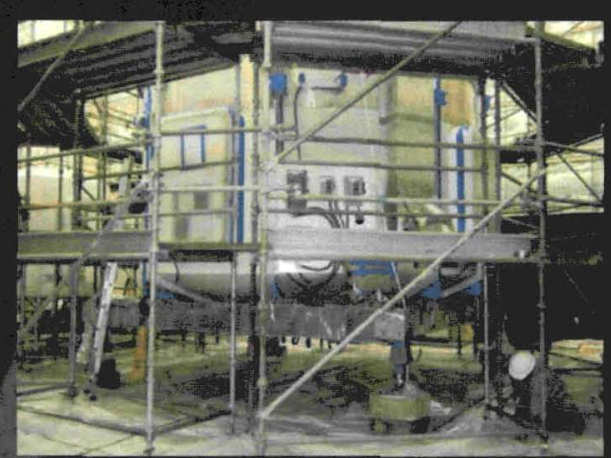

HDU Prepared for Insulation Application

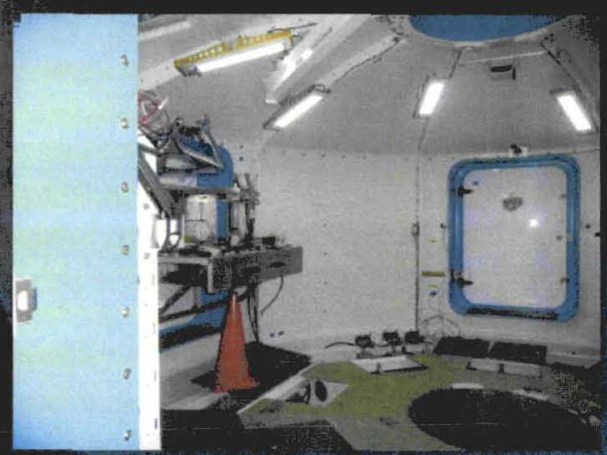

LED Lighting, Sensor Integration

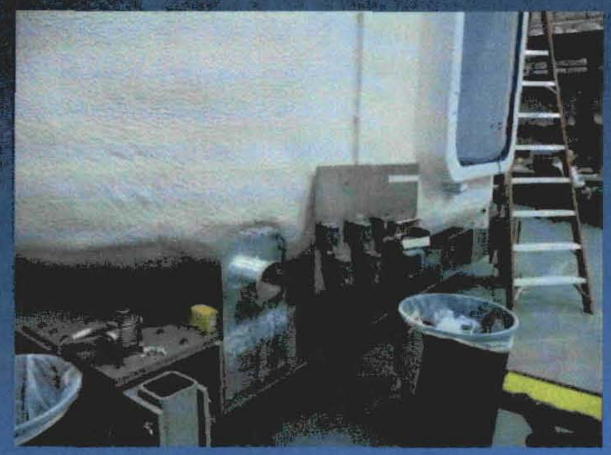

HDU Interfaces to Airlock

Jerad C. Merbitz, NASA-KSC, AIAA Space 2010, Aug 30 - Sep 2, 2010

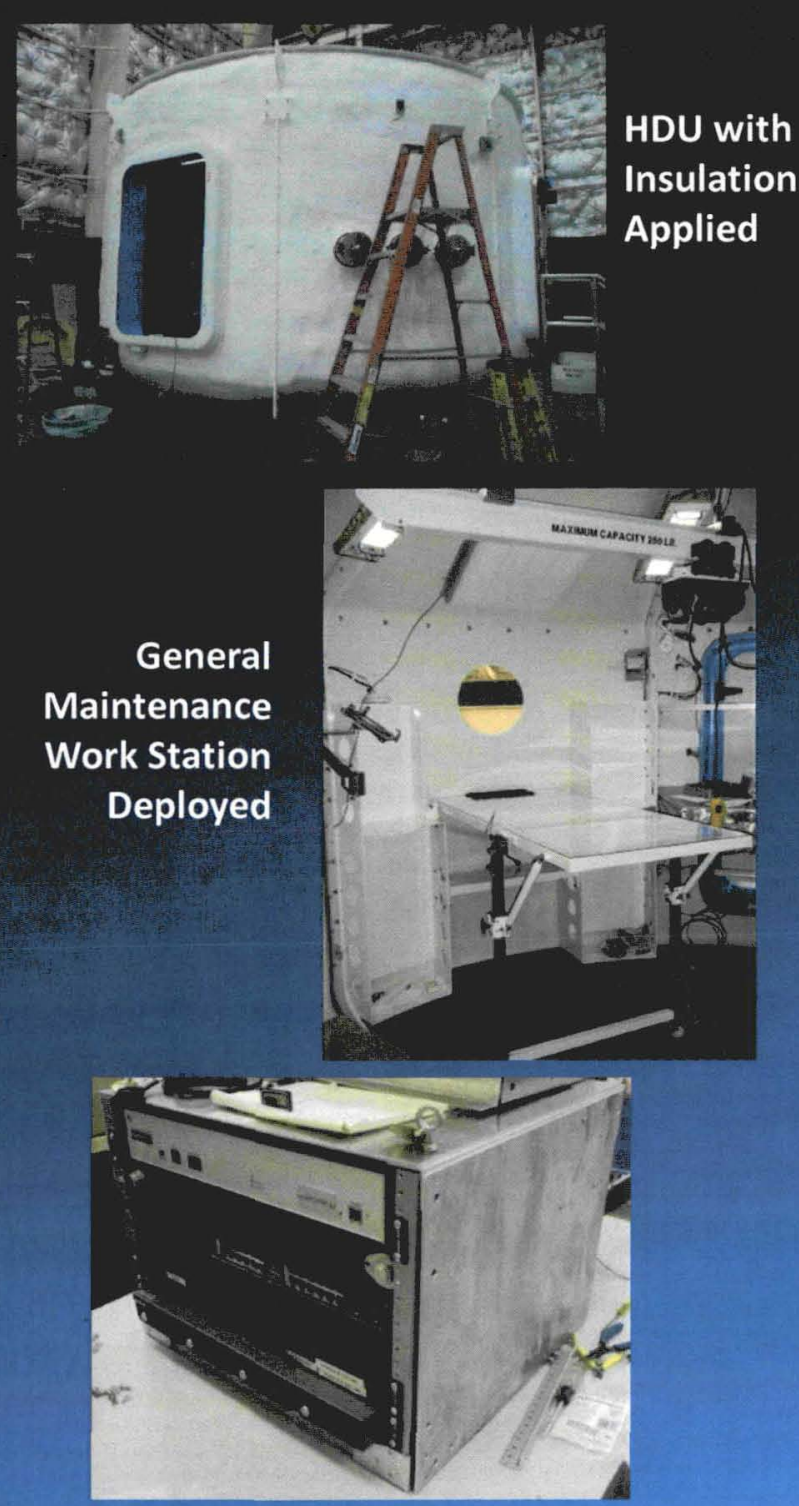

Avionics Rack in Development

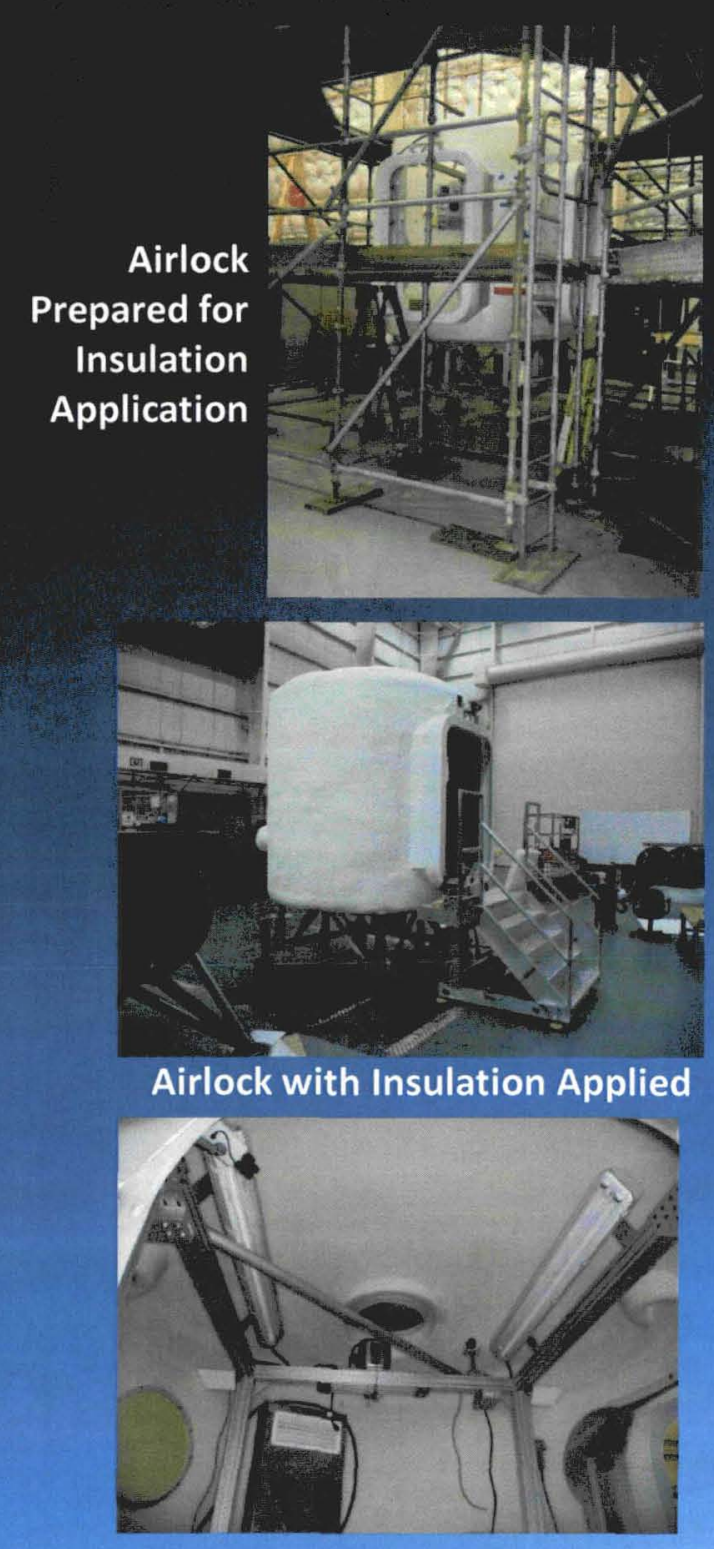

Airlock Internal Outfitting 


\section{HDU-PEM General Maintenance Work Station}

- The General Maintenance Work Station (GMWS) is a subsystem provided by Kennedy Space Center (KSC) to supply the HDU module with a general work area that provides the crew everything necessary to perform work and maintenance.

- GMWS was an example of the utility of CAD model design

- Despite late requirements and design change inputs, the design was easily modifiable in the CAD tool and easily shared by the team for review

- The integrated HDU model allowed for evaluation of human factors and interference analysis
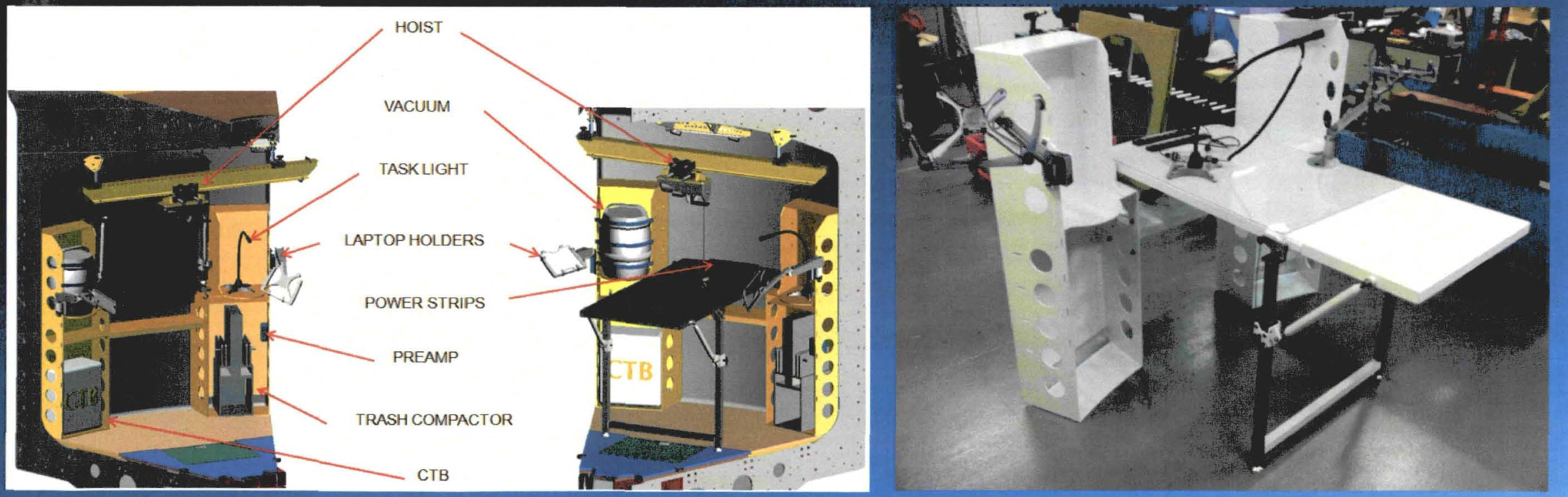


\section{HDU Test Operations}

Subsystem Checkout

Testing

(Bldg 220)

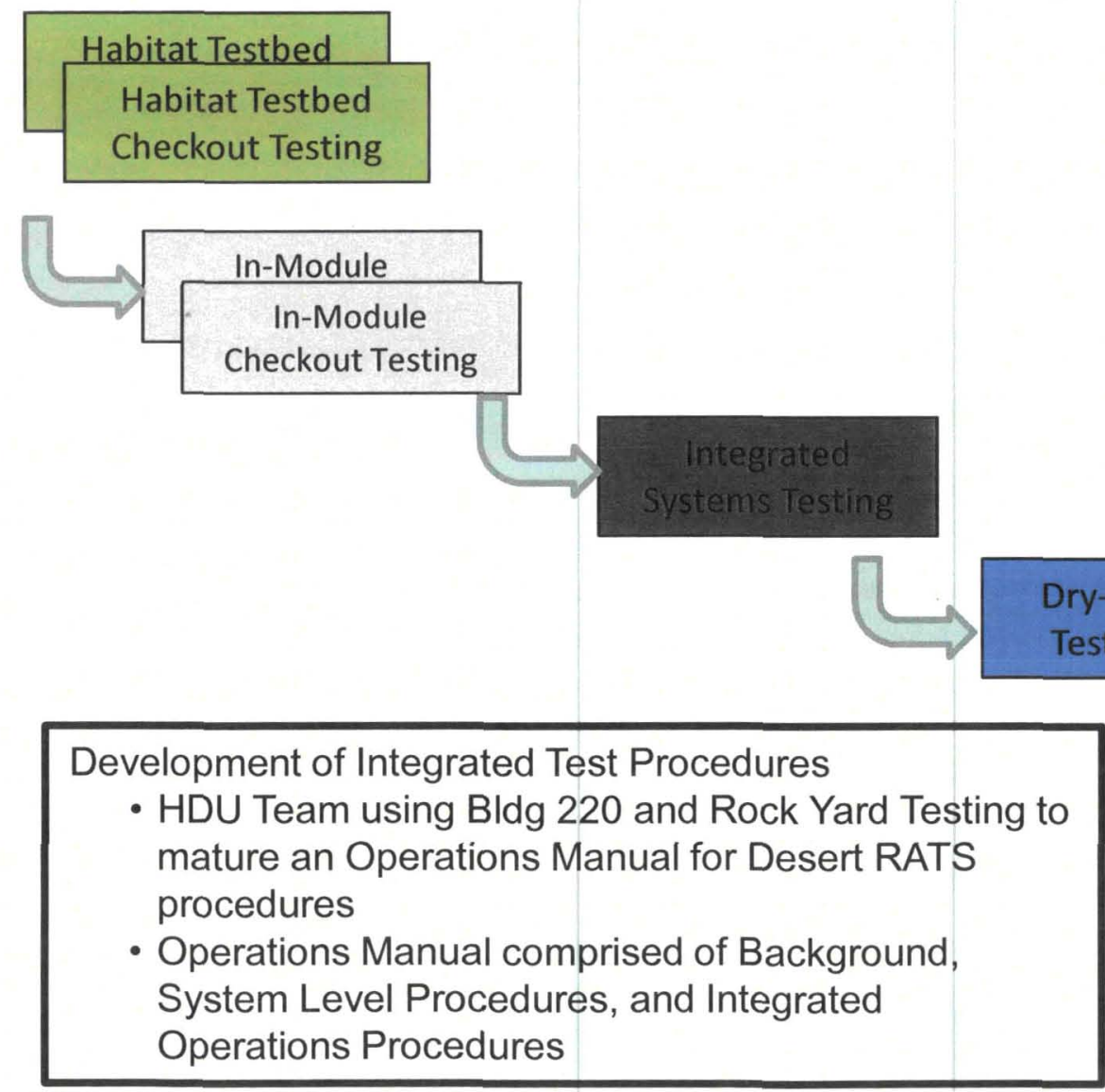

\begin{tabular}{c|c} 
Integrated & Dry-Run \\
Systems Testing & Testing \\
(Bldg 220 \& JSC & (JSC Rock \\
Rock Yard) & Yard)
\end{tabular}

Field Testing

(SP Mountain \& BPLF, AZ)
Post-Field Test

Evaluations

(B220/JSC Rock Yard)
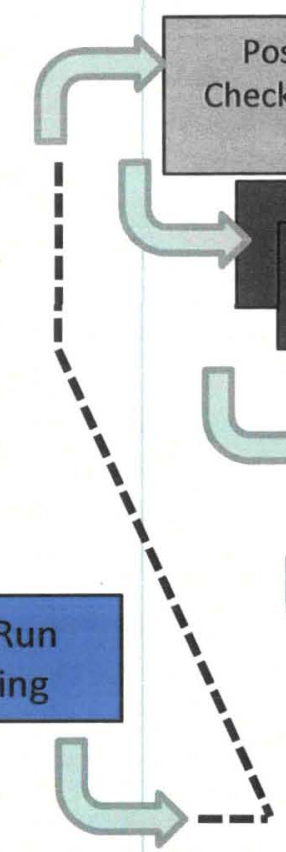

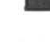

Post-Transit Checkout Testing
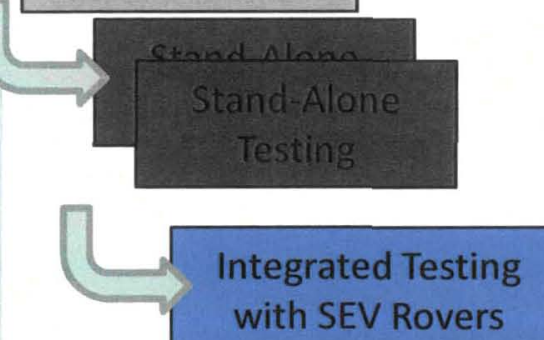

with SEV Rovers

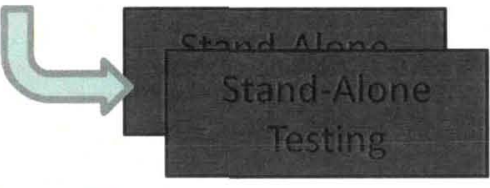

Integrated Testing with SEV Rovers 


\section{Exploration Hab (X-Hab) Challenge}

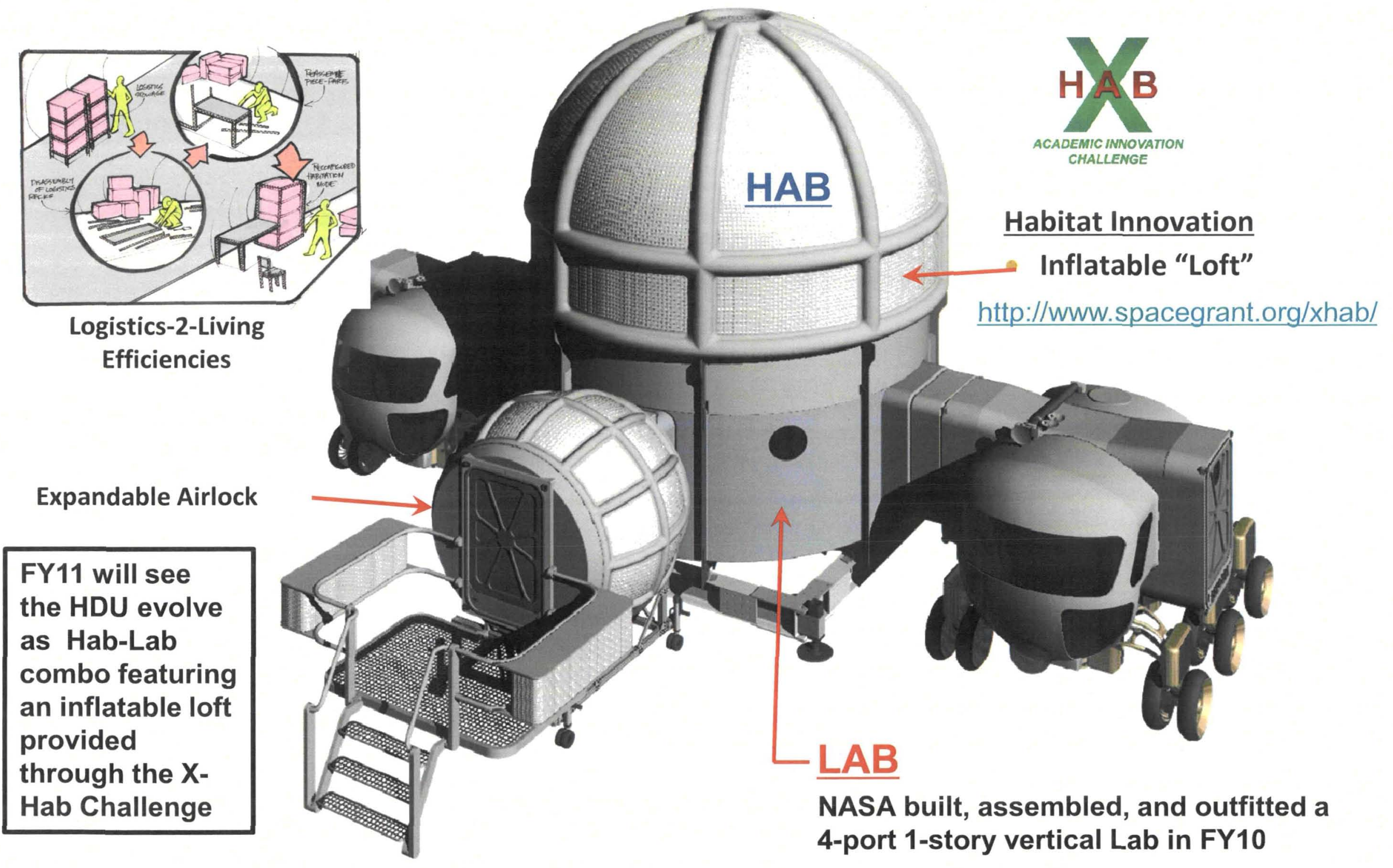




\section{Conclusion}

- Significant challenges to accelerate from a project start to a field deployment in just over a year are being addressed with several facets of the Habitat Demonstration Unit integration strategy.

- Significant effort has been made to define and document standards for system integration which will be valuable for not only the PEM but future versions of the HDU.

- The HDU project has planned scheduled activities including the use of computer aided design in the layout of systems, the use of fit-check opportunities, and the utilization of a Habitat Test-bed avionics platform to mitigate the risk of integration the systems together for the first time within the HDU.

- The entire concept of operations from the planning of the manufacturing, shipment, and integration to the field operations have all been factored into the design of the HDU to streamline the integration activities to enable to project to meet the ambitious timeline for deployment of a PEM for Desert RaTS 2010.

- These same strategies will be applied for FY11 activities to enable the utilization of the HDU as a platform for Exploration architecture validation. 
Habit

monstyakion Unit Project

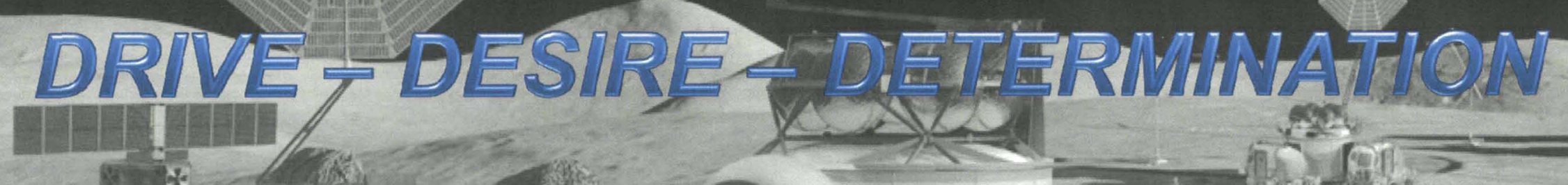

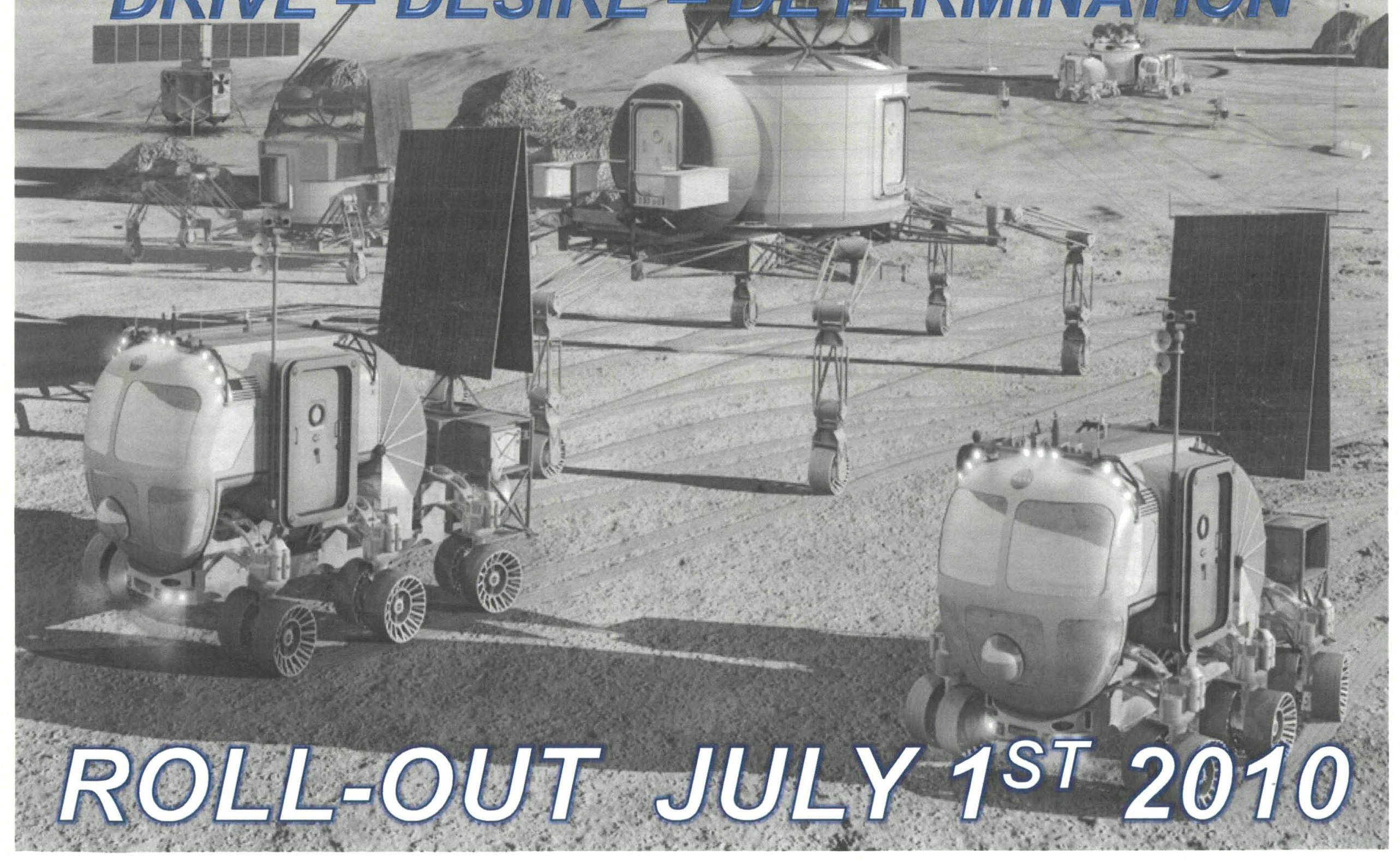

